NBER WORKING PAPER SERIES

\title{
ESTIMATING THE VALUE OF HIGHER EDUCATION FINANCIAL AID: EVIDENCE FROM A FIELD EXPERIMENT
}

\author{
Christian Belzil \\ Arnaud Maurel \\ Modibo Sidibé \\ Working Paper 23641 \\ http://www.nber.org/papers/w23641 \\ NATIONAL BUREAU OF ECONOMIC RESEARCH \\ 1050 Massachusetts Avenue \\ Cambridge, MA 02138 \\ August 2017
}

We would like to thank the Social Research and Demonstration Corporation (SRDC) for allowing us to use the data, which has been developed within the "Willingness to Borrow" project, and may be obtained directly from SRDC. Christian Belzil acknowledges financial support from the ANR "Investissement d'Avenir Labex Ecodec". We thank Peter Arcidiacono, Lance Lochner, Claude Montmarquette, Basit Zafar, and seminar participants at Cornell, CREST, Paris School of Economics, Toulouse School of Economics, as well as participants at the 2015 World Congress of the Econometric Society (Montreal), and the 2017 North American Winter Meetings of the Econometric Society (Chicago) for useful comments. Brian Clark, Melina Hillion and Jintao Sun provided excellent research assistance. The views expressed herein are those of the authors and do not necessarily reflect the views of the National Bureau of Economic Research.

NBER working papers are circulated for discussion and comment purposes. They have not been peer-reviewed or been subject to the review by the NBER Board of Directors that accompanies official NBER publications.

(C) 2017 by Christian Belzil, Arnaud Maurel, and Modibo Sidibé. All rights reserved. Short sections of text, not to exceed two paragraphs, may be quoted without explicit permission provided that full credit, including $(\odot$ notice, is given to the source. 
Estimating the Value of Higher Education Financial Aid: Evidence from a Field Experiment Christian Belzil, Arnaud Maurel, and Modibo Sidibé

NBER Working Paper No. 23641

August 2017

JEL No. I22,I23,J24

\section{ABSTRACT}

Using data from a Canadian field experiment on the financial barriers to higher education, we estimate the distribution of the value of financial aid for prospective students, and relate it to parental socio-economic background, individual skills, risk and time preferences. Our results point out that a considerable share of prospective students are affected by credit constraints. We find that most of the individuals are willing to pay a sizable interest premium above the prevailing market rate for the option to take up a loan, with a median interest rate wedge equal to 6.6 percentage points for a $\$ 1,000$ loan. The willingness-to-pay for financial aid is highly heterogeneous across students, with preferences and in particular discount factors, playing a key role in accounting for this variation.

Christian Belzil

CREST

5 Avenue Henri Le Chatelier

91120 Palaiseau

France

and Ecole Polytechnque and IZA

christian.belzil@polytechnique.edu

Arnaud Maurel

Department of Economics

Duke University

213 Social Sciences Building

Box 90097

Durham, NC 27708

and NBER

apm16@duke.edu
Modibo Sidibé

Department of Economics

Duke University

213 Social Sciences Building

Box 90097

Durham, NC 27708

modibo.sidibe@duke.edu 


\section{Introduction}

Despite inconclusive evidence, many education policies are based on the premise that borrowing constraints preclude students from a modest background to access and persist in higher education. Quantifying the importance of credit constraints in this context is a particularly challenging task, primarily because in most datasets one cannot directly identify the set of students who are constrained. In this paper, we propose a novel empirical strategy based on the estimation of the distribution of the willingness-to-pay for higher education financial aid.

We specify and estimate an educational financing decisions model using data from a field experiment that was conducted in several Canadian high schools between 2008 and 2009. The experiment consists of a sequence of choices between a cash payment and various types of financial aid: single loan, single grant and hybrid package composed of a loan and a grant. ${ }^{1}$ Loan conditions were similar to the Federal Canadian Student Loan Program. Financial aid packages varied from $\$ 500$ - $\$ 4,000$ and represented a high fraction of yearly tuition at any of the Canadian universities. ${ }^{2}$ Therefore, these financial packages remove or reduce any potential liquidity constraints by providing education financing ahead of high-school graduation. As a consequence, prospective students facing liquidity constraints are likely to attach a significant value to the opportunity of receiving a loan at the market rate, while those who do not perceive financial constraints will regard those opportunities as redundant. In the paper we use this observation to test for the existence of frictions in the market for college loans.

We formulate the decision to accept a financial aid package as an intertemporal problem. The structure of our model is simple and may be described as follows. Young individuals, endowed with Constant Relative Risk Aversion (CRRA) preferences, must

\footnotetext{
${ }^{1}$ This experiment uses tools from standard lab experiments and applies them to a sample of individuals drawn from the population of interest. As such, it qualifies as an "artefactual field experiment" as defined in Harrison and List (2004).

${ }^{2}$ Amounts are in Canadian dollars. The average tuition was equal to $\$ 2,180$ for Quebec, $\$ 5,667$ for Ontario, $\$ 3,228$ for Saskatchewan, and $\$ 5,064$ for Manitoba, over the period covered by the experiment. Similarly, the average US in-state tuition fees charged by public 4-year institutions for 2007-2008 were US \$6,200 according to the Bureau of Labor Statistics (Spotlight on Statistics: Back to College, 2010).
} 
weigh the increase in utility generated by the acceptance of a cash payment against the expected future gain generated by a specific financial aid package. Although we do not observe the post high-school graduation decisions of agents, we can use information on their revealed preferences to infer the utility gains of accepting different financial aid packages. We derive the willingness-to-pay for financial aid opportunities, and use those estimates to uncover the distribution of the individual-specific additional rates of interest that each individual would be willing to pay to secure financial aid.

To the extent that education financing decisions are made prior to actual college enrollment, the decision to accept a financial aid package depends not only on the perceived magnitude of borrowing constraints, but also on the subjective probability of enrolling in higher education, as well as beliefs over other future outcomes such as probability of dropping-out from college. Understanding financial aid acceptance therefore requires taking into account both heterogeneity in risk aversion and discount factors, as well as financial resources provided by the family. Since the experiment was also designed to infer fundamental preference parameters for risk and time, it provides a unique opportunity to address this important question and allows us to separate the effects of preferences from other components such as skills, and parental background on the probability to accept financial aid. In the paper we investigate the role played by risk aversion and discount factors, which, thanks to the panel nature of the data, are allowed to be individual-specific, by including them as determinants of higher education financing decisions.

The majority of our sample attaches a significant value to the option of accessing higher education loans, and would be willing to trade sizable increases in current consumption in return for the option to take up a $\$ 1,000$ loan at the market interest rate in the near future. Notably, our estimates indicate that the median high school student would be willing to pay an interest rate premium of 6.6 percentage points on top of the prevailing market rate to secure a $\$ 1,000$ loan, consistent with the existence of substantial frictions in the market for college loans. The willingness-to-pay for financial aid is also found to be highly heterogeneous across students, while remaining non-negligible for the vast majority of the population. Overall, these results point to the existence of credit constraints which affect a large share of high school students in Canada. 
In terms of public policy, our estimates can be more generally interpreted as uncovering the willingness-to-pay for a counterfactual expansion in higher education financial aid offers. Since the set of financial aid offers include grants, our estimates also speak to the value of a significant reduction in university tuition fees. Students attach high values to grants. For instance, our estimation results imply that the median agent would be willing to trade a $\$ 400$ increase in current consumption against a $\$ 1,000$ reduction in tuition in the future.

Individual-specific discount factors as well as risk aversion parameters, which are very dispersed across students, play an important role in explaining the willingness-topay for higher education financial aid. A variance decomposition analysis shows that these individual preference parameters are more important than all other determinants. For instance, they are about six times more important than parental education, parental income and numeracy test score in explaining the willingness-to-pay for a \$1,000 loan. These findings highlight the importance of collecting data on individual time and risk preferences to improve our understanding of educational financing decisions and, more generally, of higher education demand.

The rest of the paper is organized as follows. In Section 2, we provide an overview of the related literature and detail our contributions. The design of the field experiment and a summary of the data are discussed in Section 3. Sections 4 and 5 describe the model and the econometric specification. Section 6 discusses the identification and the estimation procedure. The estimation results are presented in Section 7. Finally, Section 8 concludes.

\section{Background literature and contributions}

The existence and the intensity of credit constraints are among the most important issues guiding public policies aimed at stimulating human capital formation such as loans, grants and work study programs (see Lochner and Monge-Naranjo, 2012, 2016, and Heckman and Mosso, 2014 for recent surveys). In the education context, credit constraints denominate any barrier hindering potential students to finance tuition fees or consumption. At the empirical level, testing for the presence of credit constraints is challenging since borrowing restrictions are not observed in standard data sets. As 
a consequence, most of the papers have used indirect approaches.

One can distinguish four main strands in this literature. A first set of papers argue that one reason why the estimated returns to schooling using standard instrumental variable techniques may be larger than the OLS estimates is that the subpopulation of compliers tend to be more credit constrained, and thus face larger returns to schooling at the equilibrium (see, e.g., Lang, 1993, and Card, 1995). A second strand of papers test for the importance of credit constraints by estimating short-term effects of parental income on the probability of enrolling in higher education, controlling for long-run factors such as ability (see, e.g., Cameron and Heckman, 1998, Carneiro and Heckman, 2002, and Belley and Lochner, 2007). The third one estimates or calibrates structural models in which credit constraints are explicitly represented, as in Keane and Wolpin (2001), Cameron and Taber (2004), Lochner and Monge-Naranjo (2011) and Johnson (2013). Finally, Cameron and Taber (2004) and Brown, Scholz, and Seshadri (2012) analyze various other testable implications of the existence of credit constraints. With the notable exceptions of Belley and Lochner (2007), Lochner and Monge-Naranjo (2011) and Brown et al. (2012), most of these studies conclude against the existence of a significant role played by credit constraints. ${ }^{3}$

Recently, alternative approaches based on direct measures of credit constraints have been proposed. Although access to these measures provides a clear advantage to researchers, they are typically obtained at the expense of external validity. In addition, while quantifying the overall importance of education financing barriers in the economy requires evaluating their impact prior to actual college enrollments, direct measures are generally obtained from a sub-population of individuals who have already enrolled in higher education. A key reference in this literature is Stinebrickner and Stinebrickner (2008), who designed a survey of college students enrolled at Berea College (Kentucky) in order to identify those who are credit constrained and to analyze differences in college drop-out decisions. While a non-trivial fraction of the students declare that they would like to borrow money at a fair interest rate to increase their consumption

\footnotetext{
${ }^{3}$ The intuition of Belley and Lochner (2007) is that changes across the 1979 and 1997 cohorts of the NLSY in the effect of income quantiles on college enrollment provide evidence in favor of credit constraints. Their argument is primarily based on the observation that college attendance rate among the low ability individuals has increased more over time for students coming from high income families.
} 
while in school, the authors conclude that the majority of college attrition is explained by factors other than access to credit. ${ }^{4}$

In this paper, we follow another route and use rich data from a college education financing field experiment conducted among Canadian high school students to address this question. Importantly, this experiment provides us with direct measures of the opportunity cost of refusing various types of higher education financial aid packages. This unique feature of the data allows us to estimate the distribution of the monetary values associated with the option to take up college loans at the prevailing market interest rate, and then investigate the existence and intensity of credit market imperfections in this context. Indeed, in the absence of credit constraints, one would expect these values to be small or negligible. On the other hand, large values associated with the option to take up college loans are indicative of credit constraints that are anticipated by the students at the end of high school.

Our study is also related to the experimental literature dealing with the estimation of risk and time preferences, including Coller and Williams (1999), Holt and Laury (2002), Andersen, Harrison, Lau, and Rutstrom (2008) and Andreoni and Sprenger (2012) (see Frederick, Loewenstein, and O'Donoghue, 2002, for a survey). In our paper, we estimate nonparametrically the joint distribution of risk aversion parameters and discount factors. This is possible thanks to the large number of choices that are recorded for each individual, which allows us to treat both risk aversion parameters and discount factors as individual fixed-effects. It is worth noting that, in this respect, our approach stands in sharp contrast to most of the dynamic discrete choice literature, where one generally imposes the restriction that all agents share the same discount factor and the same degree of risk aversion. ${ }^{5}$ The results obtained in this paper provide clear evidence that discount factors and risk aversion parameters are highly heterogeneous across individuals, and, most importantly, that heterogeneity in

\footnotetext{
${ }^{4}$ Recent work by Delavande and Zafar (2014) investigates the role played by credit constraints in the context of university choice in Pakistan. The authors address the identification issue by directly eliciting from the individuals the university they would have chosen in the (counterfactual) absence of financial constraints, and find that those constraints play an important role.

${ }^{5}$ Notable exceptions include Arcidiacono, Sieg, and Sloan (2007) and Brodaty, Gary-Bobo, and Prieto (2014), who allow for heterogeneous discount factors and relative risk aversion, respectively.
} 
preferences plays a central role in explaining the willingness-to-pay for higher education financial aid.

\section{Data}

The data used in the paper comes from "The Millenium Foundation Field Experiment on Education Financing". The field experiment was conducted from October 2008 to March 2009. The sample, which consists of 1,248 Canadian full time senior high school students (or students enrolled in CEGEP, the equivalent of senior year of high school in Quebec), was drawn from both urban and rural sites across Canada. The students were between 16 and 18 years old at the time of the experiment. The experiment was funded by the Canada Millennium Foundation, a public enterprise created by the Canadian federal government, and was carried jointly by The Social Research and Demonstration Corporation (SRDC, Ottawa, Canada) and the Centre Interuniversitaire de Recherche en Analyse des Organisations (CIRANO, Montreal, Canada). ${ }^{6}$

The experiment was conducted using pen and paper choice booklets as well as simple random sampling devices like bingo balls and dice. Project cost considerations suggested that participants be drawn from locations with convenient travel connections from the SRDC Ottawa and CIRANO Montreal offices. Manitoba, Saskatchewan, Ontario and Quebec were the selected provinces. The implementation team was able to carry out work in urban and rural schools in each of the four provinces. ${ }^{7}$ Table A4

\footnotetext{
${ }^{6}$ See Montmarquette and Johnson (2015), who designed the experiment used in the present paper, for an extensive description of the Millenium Field Experiment. In this paper the authors estimated a reduced-form model of the decision to take up loans. They focus on the notion of loan aversion, and conclude against the existence of sizable loan aversion in this context.

${ }^{7}$ Experiment staff was granted access to the high schools and cooperated with student services staff to recruit and schedule senior students. Sessions took place during school hours (over two days). Participation to a Web survey and parental consent were required to participate in the experimental session. The experimental sessions were held in controlled environments including classrooms, libraries, career counseling rooms, activity rooms and auditoriums. All rooms were held on the campus where the student attended classes. The planned optimal number of participants per session was between 20 and 25 allowing the entire urban subject pool to be contained in 50 sessions. A total of 75 sessions were conducted with 50 as the maximum number of participants in any session. For showing up on time, each participant received a $\$ 20$ fee. Supplementary information regarding aspects of the experiment that we do not model may be found in Montmarquette and Johnson (2015).
} 
in Appendix A provides a descriptive overview of our sample. ${ }^{8}$

The experiment consists of three parts. First, students must answer a set of questions aimed at measuring their rate of time preference. In those questions, individuals are offered a choice between two payments of different values to be made at different points in time. In our analysis we use the 24 questions that provide a cash payment within a day or a week (see Table A1 in Appendix A). A second set of questions relate to the measurement of risk attitudes. Specifically, students are presented with a sequence of 55 binary choices between two lotteries in which risk is objectively stated (see Table A2). Finally, the third group of questions is a sequence of choices between a cash payment to be paid within one week from the day the experiment was carried, and the option to take up a specific financial aid package covering future educational expenses. These questions play a key role in our empirical strategy. Should the student decide to exercise this option, the financial aid package is to be paid conditional on enrolling in a full-time program at any higher education institution in the country (within two years). ${ }^{9}$ Importantly, choices were incentivized as students were paid for one randomly drawn decision at the end of the session.

Overall, three types of financial aid packages were offered, namely grants, loans and hybrid loans which combine a loan and grant. In the paper we use a total of 17 financial aid decisions for each respondent, with 5 choices with a single loan offer, 7 choices with a single grant offer, and 5 hybrid loan offers. These decisions are summarized in Table A3 in Appendix A. ${ }^{10}$

Cash alternatives varied from $\$ 25$ to $\$ 700$, while grants and loans varied from $\$ 400$ to $\$ 4,000$. The variations in cash amounts and in the nature and the size of financial

\footnotetext{
${ }^{8}$ Although the first objective of the designers of the experiment was not to achieve national representativity, comparison with nationally representative data from the Youth In Transition Survey (YITS) suggests that the resulting sample is largely representative of the subpopulation of Canadian youths who have obtained at least a high school degree. Belley, Frenette, and Lochner (2014) provide a detailed discussion of the YITS data in the context of post-secondary attendance decisions in Canada. See also Hansen and Liu (2013) who report the characteristics of individuals from the YITS sample separately by schooling level. Overall, the composition of our sample is qualitatively similar to the respondents of the YITS who have obtained at least a high school degree.

${ }^{9}$ Over this period in Canada, the transition rate from high school to higher education was around $85 \%$ (see Belley et al., 2014).

${ }^{10}$ It is worth noting that more than $98 \%$ of the individuals in our sample did not exhibit any violation of transitivity of preferences, supporting the idea that respondents took the survey seriously.
} 
aid packages play a crucial role in our analysis. At the outset, it should be clear that these amounts are quite significant in the Canadian context. For instance, over the period considered, a grant of $\$ 2,000$ in 2008 would have covered $65 \%$ of yearly fee at University of Western Ontario and Queen's University, and almost 100\% at McGill University and Université de Montréal. Importantly for our empirical strategy, loans in the experiment were offered at the same interest rate as in the Federal Canadian Student Loan Program. At the time of the experiment, this rate, which we sometimes simply refer to in the paper as the "market rate", was equal to 5.7\%. ${ }^{11}$ In Appendix A we provide additional details about how the grants and loans were administered as part of the experiment.

\subsection{Describing the take-up rates}

To describe the sensitivity of individual take-up to financial aid structure and cash payments, we plot below the take-up rates associated with various combinations of grants and loans, against specific cash payments. In Figure 1, the take-up rates are those obtained when the alternative cash payment was $\$ 25$ and $\$ 700$, respectively. ${ }^{12}$ As expected, the take-up rates are inversely related to the amount of cash payment. For instance, $90 \%$ of individuals opted for a $\$ 1,000$ grant when offered a $\$ 25$ cash payment, while only $40 \%$ opted for a $\$ 1,000$ grant when offered a cash payment of $\$ 700$. Those differences in take-up rates are very similar for the three financial aid packages considered in this figure $(\$ 1,000$ grant, hybrid $\$ 1,000$ loan combined with $\$ 1,000$ grant, and $\$ 1,000$ loan). Figure 2 reports the take-up rates for various sizes and types of financial aid packages and for a $\$ 300$ cash payment. This figure shows that, for all three types of packages, take-up rates increase with the size of the financial aid. However, the increase in take-up rates is relatively modest after $\$ 1,000$. Figure 2 shows that the marginal increase in take-up rates for additional financing is relatively small,

\footnotetext{
${ }^{11}$ The interest rates of the loans offered through the experiment were also similar to the rates offered by Canadian Charter banks such as the Royal Bank, the Toronto Dominium Bank and the Bank of Montreal, within their private education loan programs. For students enrolled in specific fields such as Medicine or Engineering, private education loans were sometimes offered at lower rates than federal loans. For more details, see the Annual Report about the Canadian Student Loans Program (Human Resources and Skills Development Canada, 2010-2011).

${ }^{12} \mathrm{~L}$ stands for loan and $\mathrm{G}$ for grant.
} 
with take-up rates respectively equal to $76 \%$ for a $\$ 2,000$ grant and $84 \%$ for a $\$ 4,000$ grant, against $68 \%$ for a $\$ 1,000$ grant and $39 \%$ for a $\$ 500$ grant. An explanation for those take-up rates being significantly below 1 even for a $\$ 4,000$ grant is that not all individuals in our sample intend to enroll in higher education, and as a consequence, some individuals will always value more current consumption over higher education financing opportunities. Besides, even some of the students expecting to enroll in higher education may choose a significantly smaller amount of cash payment over the option to take up a grant as the latter can be used to pay for educational expenses only. A similar pattern can be observed for single loan offers, as the take-up rate for $\$ 1,000$ loan is $11 \%$, compared to $17 \%$ and $24 \%$ for $\$ 2,000$ and $\$ 4,000$ loans, respectively.

Figures 1 and 2 also show that take-up rates for a grant of value $x$ are very similar, and in fact always slightly higher, than for a hybrid financial package offering an additional loan of value $x$. This pattern likely reflects the fact that taking up a hybrid financial aid package in practice entails taking up both the loan and the grant associated with it, and thus paying the interests on the loan component. Depending on the expected future consumption profile as well as the existence and intensity of credit constraints, individuals may rationally attach a higher value to a grant offer than to a hybrid package adding a loan to the grant. Besides, that the take-up rates for single loan offers increase with the loan amounts, while take-up rates for hybrid packages are lower than for grants, points to the future value of financial aid being non-linear in post-college repayment amounts. The choice model we consider in the next section allows for such non-linearities. 
Figure 1: Take-up rates

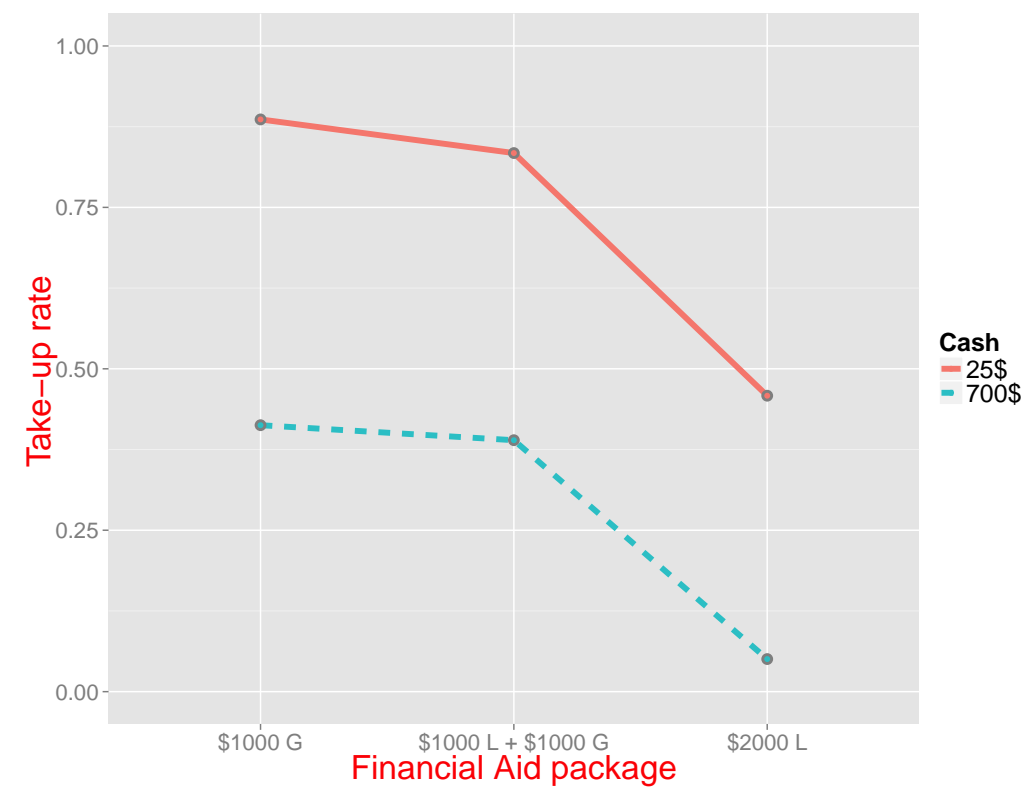

Figure 2: Take-up rates against $\$ 300$

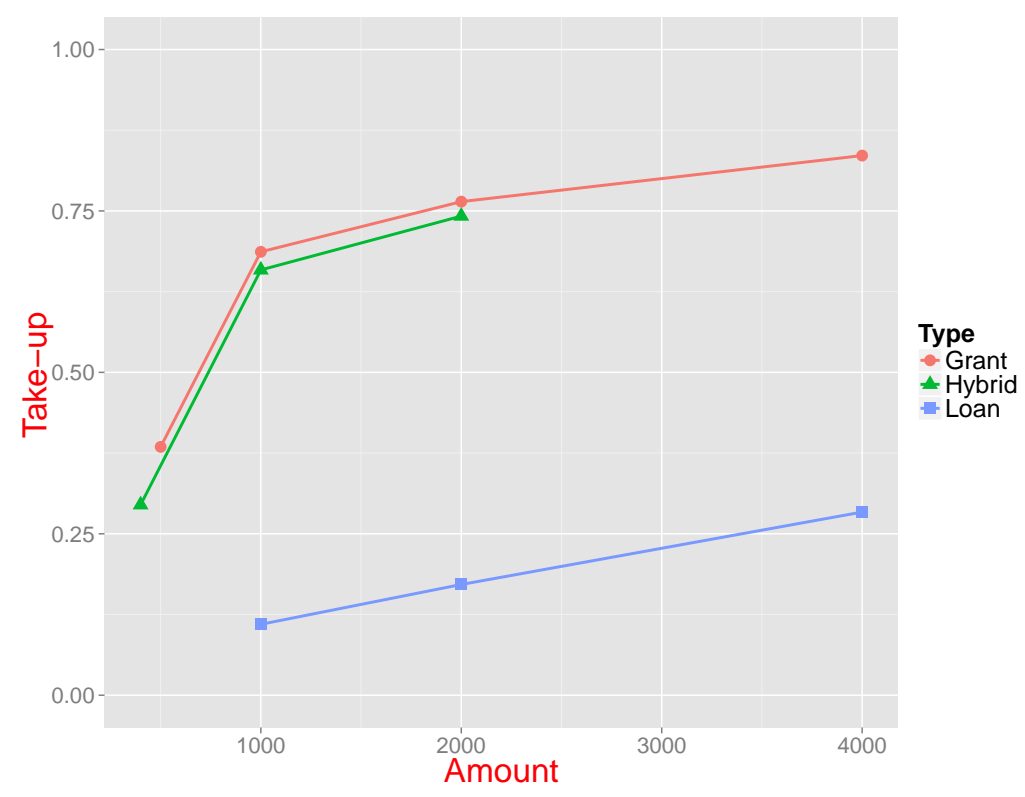




\section{The model}

In this section we present a simple choice model which, combined with our experimental data, will allow us to quantify the willingness-to-pay for financial aid opportunities. Namely, we assume that preferences over consumption are represented by a CRRA utility function. For each student $i$, the utility of consumption $c$ is given by:

$$
u\left(c, \theta_{i}\right)= \begin{cases}\frac{c^{1-\theta_{i}}}{1-\theta_{i}} & \text { if } \theta_{i} \neq 1 \\ \log (c), & \text { if } \theta_{i}=1\end{cases}
$$

where $\theta_{i}$ denotes the individual-specific risk aversion parameter.

The large number of questions available from the experiment (96 in total) allows us to treat relative risk aversion rate as well as the annual discount factors as individualspecific parameters. Because individuals differ not only in their preferences, but also in their financial resources, we further allow for individual specific consumption endowments. In the rest of the section we follow the structure of the experiment and present the choice equations separately for each group of questions.

\subsection{Time preference}

A first set of questions (indexed by $q=1, \ldots 24$ ) is devoted to measuring the subjective discount rate and consists of a sequence of choices between two alternatives: an early cash payment denoted by $a_{0 q}$ to be paid $t_{0 q}$ months from now, and another cash payment denoted by $a_{1 q}$, and to be paid $t_{1 q}$ months from now. We denote by $Y_{i q}$ a dummy variable which is equal to 1 if individual $i$ chooses the early cash payment. Questions differ with respect to the amount of the cash payment, and the periods at which the earlier or later cash payments would be paid.

We express individual $i$ 's probability to choose consumption at period $t_{0 q}$ versus 
period $t_{1 q}$ using a simple two-period consumption model:

$$
\begin{aligned}
\operatorname{Pr}\left(Y_{i q}=1\right)=\operatorname{Pr}\left\{\beta _ { i } ( t _ { 0 q } ) \left[u \left(c_{i}\right.\right.\right. & \left.\left.+a_{0 q}, \theta_{i}\right)-u\left(c_{i}, \theta_{i}\right)\right] \\
& \left.+\beta_{i}\left(t_{1 q}\right)\left[u\left(c_{i}, \theta_{i}\right)-u\left(c_{i}+a_{1 q}, \theta_{i}\right)\right]+\varepsilon_{i q}>0\right\}
\end{aligned}
$$

where $\varepsilon_{i q}$ is an idiosyncratic preference shock and $c_{i}$ the individual background consumption. The distributional assumptions and specification of the background consumption are discussed in Section 5. Finally, the individual discount rate applied for a payment to be received $t_{q}$ months from now is assumed to be given by:

$$
\beta_{i}\left(t_{q}\right)=\frac{1}{1+\frac{t_{q}}{12} \cdot r_{i}}
$$

where $r_{i}$ denotes the individual annual subjective interest rate.

\subsection{Risk aversion}

A second set of questions relate to the measurement of the degree of relative risk aversion. In each of these questions, individuals are offered to choose between two alternatives, namely a lottery offering $a_{0 q}^{1}$ with probability $p_{q}$ and $a_{0 q}^{2}$ with probability $1-p_{q}$, and another lottery offering $a_{1 q}^{1}$ with probability $p_{q}$ and $a_{1 q}^{2}$ with probability $1-p_{q}$. Questions differ according to the state contingent cash payments $\left(a_{0 q}^{1}, a_{0 q}^{2}, a_{1 q}^{1}, a_{1 q}^{2}\right)$ and probabilities $\left(p_{q}, 1-p_{q}\right){ }^{13}$ The generic choice probability for the first alternative is given by:

$$
\begin{aligned}
\operatorname{Pr}\left(Y_{i q}=1\right)=\operatorname{Pr} & \left\{p_{q} \cdot\left(u\left(c_{i}+a_{0 q}^{1}, \theta_{i}\right)-u\left(c_{i}+a_{1 q}^{1}, \theta_{i}\right)\right)\right. \\
+ & \left.\left(1-p_{q}\right) \cdot\left(u\left(c_{i}+a_{0 q}^{2}, \theta_{i}\right)-u\left(c_{i}+a_{1 q}^{2}, \theta_{i}\right)\right)+\varepsilon_{i q}>0\right\}
\end{aligned}
$$

\footnotetext{
${ }^{13}$ As is standard in the experimental literature, we assume that individuals consume the windfall gain immediately upon reception.
} 
where $\varepsilon_{i q}$ is an idiosyncratic preference shock, and $q=25, \ldots 79$.

\subsection{Choices between consumption and education financing}

The third group of questions is a sequence of choices between a cash payment to be paid within one week, and a specific financial aid package covering educational expenses.

In order to interpret individual choices between cash payments and educational financial aid, we specify a stylized two-period model. Period 0 refers to the time when high school students are asked to choose between consumption and an education financing package, while period 1 refers to the residual life-cycle starting from high school graduation. For each choice, individuals must decide between a cash payment and a financial aid package which is to be paid conditional on higher education enrollment in period 1.

This structure of the model is as follows. Let $a_{0 q}$ and $a_{1 q}$ be the cash payment and financial aid transfer in question $q$. The potential financial aid offer $\left(a_{1 q}\right)$ offered in period 0 and to be paid at the beginning of period 1 is characterized by a two-element vector, denoted by $\left(g_{q}, \ell_{q}\right)^{\prime}$ where $g_{q}$ is the amount of the grant and $\ell_{q}$ the amount of the loan. ${ }^{14}$ The choice variable $Y_{i q}$ is equal to 1 when an individual chooses financial aid $a_{1 q}$, and 0 if she accepts consumption $a_{0 q}$. As a consequence, the initial period consumption $c_{0 i q}$ is given by

$$
c_{0 i q}=c_{i}+a_{0 q} \cdot\left(1-Y_{i q}\right)
$$

The period 0 utility, denoted by $W($.$) , of accepting or rejecting the financial aid is$ then given by:

$$
\begin{aligned}
& W\left(Y_{i q}=1\right)=u\left(c_{i}, \theta_{i}\right)+\varepsilon_{1 i q} \\
& W\left(Y_{i q}=0\right)=u\left(c_{i}+a_{0 q}, \theta_{i}\right)+\varepsilon_{0 i q}
\end{aligned}
$$

where $\varepsilon_{0 i q}$ and $\varepsilon_{1 i q}$ represent choice specific preference shocks.

\footnotetext{
${ }^{14}$ For instance, an offer consisting of a grant has an entry equal to 0 for $\ell$, while a loan has an entry equal to 0 for $g$. A hybrid offer that includes both a grant and a loan has a positive entry for both.
} 
Because we do not have data on actual choices exercised in subsequent periods, we focus on the estimation of the difference between future components of the utilities of accepting and rejecting financial aid. The intertemporal utilities of accepting and rejecting financial aid are given by $u\left(c_{i}, \theta_{i}\right)+\varepsilon_{1 i q}+\beta_{i} E V_{i q}\left(Y_{i q}=1\right)$ and $u\left(c_{i}+a_{0 q}, \theta_{i}\right)+$ $\varepsilon_{0 i q}+\beta_{i} E V_{i q}\left(Y_{i q}=0\right)$, respectively, where the future components $E V_{i q}\left(Y_{i q}=1\right)$ and $E V_{i q}\left(Y_{i q}=0\right)$ are the expected lifetime utilities associated with each choice.

In practice, expected future value terms associated with each alternative $Y_{i q} \in\{0,1\}$ depend on individual beliefs about a range of future outcomes, some of them being alternative specific. Notably, those beliefs include the subjective probabilities of enrolling in higher education conditional on receiving the financial aid offer $a_{1 q}$, and conditional on not receiving the financial aid offer, for the alternatives $Y_{i q}=1$ and $Y_{i q}=0$ respectively. The expected future value terms in principle also depend on the perceived availability of higher education financing opportunities outside of the experiment, as well as possibly on beliefs over other future outcomes such as the probability of dropping-out from college. As those outcomes are not observed in the data, we treat those future components as unknown functions of parental socioeconomic background and individual skills, as well as risk and time preferences. A key advantage of this approach relative to a more standard dynamic discrete choice model is that it avoids strong and untestable restrictions regarding the beliefs of the individuals and their evolution over the life cycle. ${ }^{15}$

Under these assumptions, agent $i$ 's probability to accept the financial aid package proposed at question $q$ is given by

$$
\operatorname{Pr}\left(Y_{i q}=1\right)=\operatorname{Pr}\left\{u\left(c_{i}, \theta_{i}\right)-u\left(c_{i}+a_{0 q}, \theta_{i}\right)+\beta_{i} \cdot \psi_{i q}+\varepsilon_{i q}>0\right\}
$$

where $\psi_{i q}=E V_{i q}\left(Y_{i q}=1\right)-E V_{i q}\left(Y_{i q}=0\right)$ denotes the expected future utility gain associated to accepting financial aid, and $\varepsilon_{i q}=\varepsilon_{1 i q}-\varepsilon_{0 i q}$.

\footnotetext{
${ }^{15}$ An alternative approach would be to elicit beliefs about counterfactual future schooling choices and consumption paths. In the higher education context, notable references include Arcidiacono, Hotz, and Kang (2012), Stinebrickner and Stinebrickner (2014), Wiswall and Zafar (2015a, 2015b) and Zafar (2013) who use subjective expectations data to examine the determinants of college major choice.
} 


\section{Specification}

In the following, we assume that the idiosyncratic shocks are independent across individuals and questions, and identically distributed within each of the three groups of questions following a normal distribution with mean zero. We summarize in the rest of the section the specification of the background consumption and the expected future utility gain of accepting financial aid.

\subsection{Background consumption}

Until now, we have simplified the exposition by considering for each individual a unique background consumption variable $c_{i}$. However in order to capture contextual differences across groups of questions, we allow the background consumption levels, and therefore also the marginal utility of consumption to vary across groups of questions. ${ }^{16}$ Specifically, for each group of questions $k$ (where $k \in\{1,2,3\}$ indexes the questions related to time preference, risk aversion and education financing, respectively), we denote the individual background consumption by $c_{i}^{k}$, which is assumed to depend on a vector of individual and family background characteristics denoted by $Z_{i}$ :

$$
c_{i}^{k}=\exp \left(\gamma_{k} Z_{i}\right)
$$

The vector $Z_{i}$ includes an intercept and a set of individual characteristics, namely gender, parental income $(20-40 \mathrm{~K}, 40-60 \mathrm{~K}, 60-80 \mathrm{~K}, 80-100 \mathrm{~K}$ and more than $100 \mathrm{~K}$ Canadian dollars per year), parental education (high school, vocational college and college) of the respondent of the parental survey, Canadian citizenship, place of residence (Quebec, Ontario, Saskatchewan, and a dummy for rural location) and family composition (existence of siblings younger or older than 18). ${ }^{17}$ This flexible specification allows each of these characteristics to have different weights within each group of questions.

\footnotetext{
${ }^{16}$ In practice, allowing $c_{i}$ to be specific to each of the three groups of questions proved important in fitting the financial aid choice data.

${ }^{17}$ There are 269 individuals with missing income data, and 146 individuals with missing education data. We use a Gibbs sampling algorithm to impute those missing information using age, gender, location, income, education, citizenship variables in the full sample.
} 


\subsection{Approximation of the future component}

The expected future utility gain of accepting financial aid $\left(\psi_{i q}\right)$ is a key component of the model. Standard structural dynamic estimation would require to posit a parametric form of the utility of potential future schooling choices as well as all the probability distributions that characterize the subjective beliefs of agents about future returns to education and experience. In this paper, we take another route and assume instead that the future component may be approximated by a parametric function that depends on the loan and grant amounts, time and risk preference parameters, skills (as measured by numeracy test scores), geographical location, parental income and education. We estimate this function using a flexible polynomial incorporating those variables in level and square as well as various interactions. ${ }^{18}$

\section{Identification and estimation}

In this section we first discuss the sources of identification of the key parameters of the model, before turning to the estimation procedure.

\subsection{Identification}

We start by informally discussing the sources of identification of the individual time preference and risk aversion parameters, before turning to the parameters of the expected future utility gain of accepting financial aid. We highlight below the main features of the experiment and of the model that are key to identification. While the experiment does provide us with separate sources of identification for those different sets of parameters, (point-)identification remains parametric in the sense that it relies

\footnotetext{
${ }^{18}$ The exact specification is given in Appendix B. Interaction between risk aversion and discount factor, squared terms in those preference parameters, and dummies for the existence of siblings younger or older than 18 are excluded from this specification as they were not statistically significant when we allowed them to enter the future component. Our approach is in line with Geweke and Keane (2000), who advocate the estimation of the future component of the value function using a polynomial which records the movement of state variables implied by the law of motion. However, in contrast with Geweke and Keane (2000), we account for heterogeneity in individual preferences and incorporate time and risk preference parameters in the polynomial.
} 
on the distributional assumptions made on the idiosyncratic shocks. ${ }^{19}$

First, the risk aversion parameters are primarily identified from the sequence of choices described in Section 4.2 between two lotteries that differ in the cash payments and the probabilities associated with each payment. Importantly, variation across individuals in time preferences does not confound the identification of the risk aversion parameters here since all of the state-contingent cash payments are immediate.

The main sources of identification of the individual discount rates are the choices between earlier and later cash payments that are described in Section 4.1. However, given that in our model individuals are endowed with non-linear CRRA preferences over consumption, part of this variation may of course also reflect heterogeneity across individuals in risk aversion. This highlights the importance of having access to choices that only depend on risk aversion, and not on discount factors.

Finally, having identified the time and risk preference parameters from the choices described above, the expected future utility gains of accepting financial aid (versus cash payment) are identified from the choices between immediate cash payment and education financial aid that are modeled in Section 4.3. Specifically, under our parametric assumptions, the expected future utility gains associated with the various types of financial aid are identified using the variation in take-up rates across discount rates. It is interesting to note that individual-specific discount rates effectively play the role of an exclusion restriction in this context, in that they only affect the choices through the future component of the utility. As such, aside from being of interest in its own right, the distribution of discount rates plays an important role in the identification of the willingness-to-pay for different financial aid packages.

\subsection{Estimation}

The model is estimated by maximum likelihood under the assumption that the error terms are independent across individuals and across questions, and identically distributed within each group of equations following a normal distribution with

\footnotetext{
${ }^{19}$ This should not come as a surprise since binary choice models are generally not point-identified without making distributional assumptions on the error term. Note that this is true even if the parameters of interest are not individual-specific (see, e.g., Magnac and Maurin, 2008).
} 
mean zero. ${ }^{20}$ Under these assumptions and keeping the conditioning on background characteristics and numeracy score implicit, the log-likelihood is given by: ${ }^{21}$

$$
\sum_{i=1}^{1,248} \sum_{q=1}^{96} Y_{i q} \log \left(\operatorname{Pr}\left(Y_{i q}=1\right)\right)+\left(1-Y_{i q}\right) \log \left(1-\operatorname{Pr}\left(Y_{i q}=1\right)\right)
$$

where for each group of questions the choice probabilities $\operatorname{Pr}\left(Y_{i q}=1\right)$, which are given in Equations (2), (3) and (6) above, take a probit form. ${ }^{22}$

\section{Results}

We present the estimation results as follows. The first part is devoted to the distributions of risk aversion and discount factors, and of the background consumption levels. The second part discusses the estimates of the expected future utility gain of accepting financial aid, for various types of financial packages. In the third part, we present the model fit. We introduce and discuss the willingness-to-pay for financial aid in Part 4, and then discuss the implications of these results in terms of credit constraints. Finally, we investigate the relative importance of family background characteristics, individual skills as well as time and risk preferences as determinants of the willingness-to-pay for financial aid. ${ }^{23}$

\footnotetext{
${ }^{20}$ Although the error terms are assumed to be independent across questions, individual choices are correlated across questions through the individual-specific risk and time preference parameters, and of course via their observed background characteristics too.

${ }^{21}$ In practice, we use a multi-step procedure to derive starting values in the region of the global optimum. The first step consists of estimating risk aversion and background consumption parameters using the subset of questions designed to elicit risk preferences. Holding those parameters fixed, we then estimate individual discount rates using the time preference questions. Finally, we estimate in a final step the future component of accepting the different types of financial aid using the school financing decisions. We use the outcomes of these three steps as starting values to estimate the full model via a single step maximum likelihood. Standard errors are estimated using bootstrap with 500 replications.

${ }^{22}$ Our framework corresponds to a binary choice panel data model with fixed effects, where the longitudinal dimension is given by the various questions $q$. Our MLE estimator is therefore in principle subject to the incidental parameter problem (Neyman and Scott, 1948). However, in practice we expect the incidental parameter bias to be negligibly small here given the large number of questions that are used in the estimation (96 overall for each individual).

${ }^{23}$ Estimation results for the background consumption parameters associated with the financial aid questions are reported in Appendix C. Estimation results for the other background consumption as
} 


\subsection{The distributions of risk aversion, discount factors and background consumption}

The empirical distributions of the estimated degrees of relative risk aversion, $\left(\theta_{i}\right)_{i}$, and discount factors, $\left(\beta_{i}\right)_{i}$, are reported in Figure 3, while Table 1 describes the joint distribution of the estimated relative risk aversion parameters and discount factors. Starting with risk aversion, $97.2 \%$ of the estimated risk aversion parameters are significant at $5 \%$, thus leading to the rejection of risk neutrality $(\theta=0)$ for the vast majority of the individuals in the sample. The distribution of risk aversion is skewed to the right and is characterized by a substantial degree of dispersion, as indicated by the inter-decile range ( 0.40 for the first decile and 0.85 for the last decile). Risk loving behavior $(\theta<0)$, however, is limited to 16 individuals out of 1,248 . Regarding the external validity of these results, it is worth noting that the median of the estimated risk aversion parameters (0.64) fits in the range of the relative risk aversion parameters that have been estimated, using observational data, in the literature on dynamic schooling choices. For instance, Keane and Wolpin (2001) estimate a smaller risk aversion coefficient (0.49), while Belzil and Hansen (2004) and Sauer (2004) find larger degrees of risk aversion (0.93 and 0.77 , respectively). Particularly relevant for us is the paper by Brodaty et al. (2014), who, unlike the previous studies, estimate a dynamic model of schooling decisions that allows for heterogeneous degrees of relative risk aversion across individuals. In their paper, the estimated risk aversion coefficients range between 0.6 and $0.9 .^{24}$

Turning to the time preferences, the discount factors are also found to be quite dispersed. The distribution is skewed to the left with its median (0.83) being larger than its mean (0.75). The empirical distribution of discount factors is essentially bimodal, with around $10 \%$ of our sample having an estimated discount rate lower than 0.33 , while another $40 \%$ of the sample has discount rate higher than 0.87 . This points to the co-existence of a myopic sub-population and a set of forward-looking individuals endowed with large discount factors of about 0.9. It is interesting to note

well as the future component parameters are available from the authors upon request.

${ }^{24}$ Our estimates exhibit a larger degree of heterogeneity across individuals, which may be partly due to the fact that we estimate the risk aversion parameters more flexibly than Brodaty et al. (2014) who assume the existence of a small number of heterogeneity types. 
Figure 3: Histogram of the risk aversion and discount factors

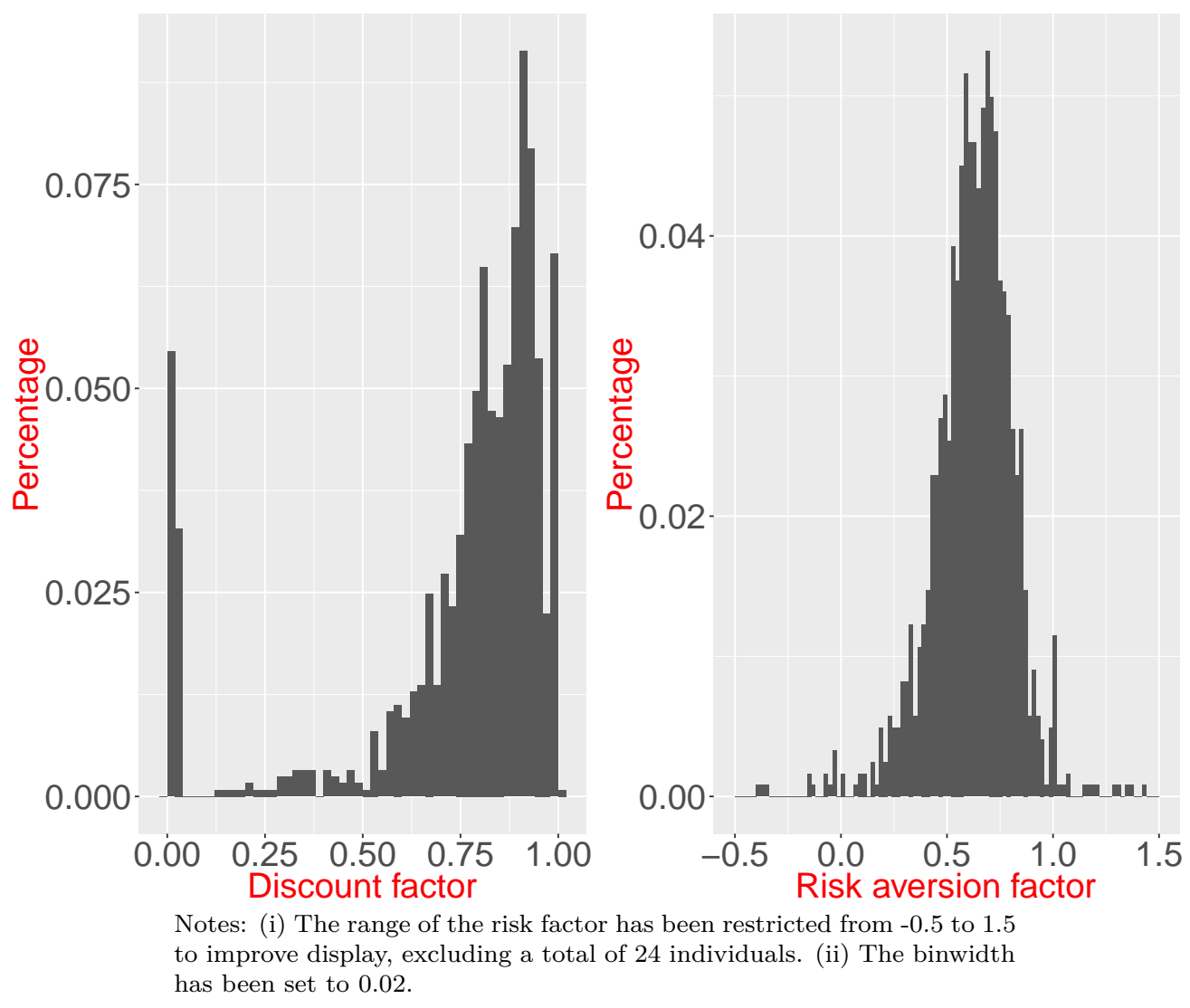


Table 1: Discount factor and risk aversion

\begin{tabular}{lll} 
& $\begin{array}{l}\text { Discount } \\
\text { Factor }\end{array}$ & $\begin{array}{l}\text { Risk } \\
\text { Aversion }\end{array}$ \\
\hline Min & 0.00 & -1.60 \\
1st Dec. & 0.33 & 0.40 \\
1st Quart. & 0.72 & 0.52 \\
40th Pct. & 0.80 & 0.60 \\
Median & 0.83 & 0.64 \\
Mean & 0.75 & 0.73 \\
SD & 0.27 & 1.00 \\
60th Pct. & 0.87 & 0.68 \\
3rd Quart. & 0.91 & 0.75 \\
9th Dec. & 0.96 & 0.85 \\
Max & 1.00 & 16.82 \\
\hline Correlation & -0.14 & \\
\hline
\end{tabular}

Table 2: Background consumption

\begin{tabular}{llll} 
& $\begin{array}{l}\text { Discount } \\
\text { Questions }\end{array}$ & $\begin{array}{l}\text { Risk } \\
\text { Questions }\end{array}$ & $\begin{array}{l}\text { Financial } \\
\text { Questions }\end{array}$ \\
\hline Mean & 3.21 & 0.58 & 237.30 \\
SD & 36.37 & 1.02 & 274.75 \\
\hline
\end{tabular}


that our mean value matches that of Andersen et al. (2008) who report, using data from an artefactual field experiment conducted in Denmark among adults aged 19 to 75 , an estimate of 0.75 (under a risk neutrality assumption), while being lower than the value estimated under risk aversion $(0.9) .{ }^{25}$

Our data also allows us to examine the joint distribution of risk aversion and discount factors. Table 1 reports a negative correlation (-0.14, significant at 1\%) between the discount rate and relative risk aversion. In the experimental economics literature, risk and time preferences are generally not elicited jointly and for this reason there exists only few estimates of the correlation between risk aversion and discount factors. A notable exception is Andersen et al. (2008), who discuss the bias affecting discount factor estimates when individuals are erroneously assumed to be risk neutral, and show that the joint elicitation of risk and time preferences results in lower discount rates estimates. Andersen et al. (2008) consider the joint distribution of risk aversion and discount rates using a parametric model in which both risk aversion and discount rates depend on observed heterogeneity and an orthogonal unobserved heterogeneity term. Consistent with our results, they report a weak positive correlation between risk aversion and impatience.

Finally, in our model, the level of background consumption allows us to capture differences in consumption levels due to heterogeneity in family background. As discussed earlier, background consumption is allowed to differ across groups of questions as well. Our estimates indicate that the consumption levels that are used to evaluate cash payments differ markedly across questions. For example, the mean reference consumption is around $\$ 3$ for discount rate questions, 50 cents for relative risk aversion choices, and $\$ 237$ for financial aid questions. The background consumption levels for the financial aid questions are also highly dispersed across individuals.

Having estimated the time and risk preferences for each individual in the sample, it is interesting to examine whether these parameters could be predicted by standard background characteristics. Table 3 below reports the results from a linear regression

\footnotetext{
${ }^{25}$ Some of the papers estimating dynamic models of schooling decisions also attempt to estimate the discount factor. Notably, Keane and Wolpin (1997) estimate for their baseline model a discount factor $(0.85)$ that is very close to the median of our estimated distribution (0.83). See Magnac and Thesmar (2002) who provide sufficient conditions under which the discount factor is identified in the context of dynamic discrete choice models.
} 
of the estimated individual-specific degrees of relative risk aversion and discount factors on a set of socio-economic background and demographic characteristics. The main takeaway from this table is that those characteristics only account for a very small fraction of the variation in risk aversion parameters and discount factors, the $R^{2}$ 's for both regressions being low (0.016 and 0.085 , respectively). Nonetheless, it is worth noting that females are significantly less forward looking and more risk averse than males. Immigrants also tend to be less forward looking, while children of college educated parents have a lower degree of risk aversion, although the coefficient is only significant at the $10 \%$ level. Finally, residents of Saskatchewan, which is the poorest region in the sample, have significantly lower discount rates.

At any rate, these results show that discount rates and risk aversion parameters are economic primitives which are mostly left unexplained by standard background and demographic characteristics. To the extent that, as discussed in Section 7.3.4, discount rates and risk aversion play a dominant role in explaining the willingness-to-pay for financial aid, this highlights the importance in this context of eliciting these preference parameters. 
Table 3: Understanding individual preferences

\begin{tabular}{|c|c|c|c|}
\hline & \multicolumn{2}{|c|}{ Regression } \\
\hline & & $\beta$ & $\theta$ \\
\hline \multicolumn{2}{|r|}{ Const } & $\begin{array}{c}0.685^{* * *} \\
(0.042)\end{array}$ & $\begin{array}{c}0.857^{* * *} \\
(0.162)\end{array}$ \\
\hline Parental & Drop-out & Ref. & Ref. \\
\hline \multirow[t]{3}{*}{ Education } & High-school & $\begin{array}{c}0.018 \\
(0.030)\end{array}$ & $\begin{array}{l}-0.157 \\
(0.116)\end{array}$ \\
\hline & Vocational College & $\begin{array}{c}0.009 \\
(0.038)\end{array}$ & $\begin{array}{r}-0.080 \\
(0.149)\end{array}$ \\
\hline & College & $\begin{array}{c}0.034 \\
(0.028)\end{array}$ & $\begin{array}{c}-0.189^{*} \\
(0.110)\end{array}$ \\
\hline Parental & $0-20 \mathrm{~K}$ & Ref. & Ref. \\
\hline \multirow[t]{8}{*}{ Income } & $20-40 \mathrm{~K}$ & $\begin{array}{c}0.023 \\
(0.037)\end{array}$ & $\begin{array}{c}0.202 \\
(0.144)\end{array}$ \\
\hline & $40-60 \mathrm{~K}$ & $\begin{array}{c}0.034 \\
(0.035)\end{array}$ & $\begin{array}{c}0.074 \\
(0.135)\end{array}$ \\
\hline & $60-80 \mathrm{~K}$ & $\begin{array}{l}-0.030 \\
(0.036)\end{array}$ & $\begin{array}{c}0.104 \\
(0.142)\end{array}$ \\
\hline & $80-100 \mathrm{~K}$ & $\begin{array}{c}0.020 \\
(0.037)\end{array}$ & $\begin{array}{c}0.142 \\
(0.144)\end{array}$ \\
\hline & $+100 \mathrm{~K}$ & $\begin{array}{c}0.030 \\
(0.036)\end{array}$ & $\begin{array}{c}0.157 \\
(0.139)\end{array}$ \\
\hline & Rural & $\begin{array}{l}0.043^{* *} \\
(0.021)\end{array}$ & $\begin{array}{l}-0.101 \\
(0.081)\end{array}$ \\
\hline & Female & $\begin{array}{c}-0.076^{* * *} \\
(0.015)\end{array}$ & $\begin{array}{l}0.118^{* *} \\
(0.057)\end{array}$ \\
\hline & Immigrant & $\begin{array}{c}-0.141^{* * *} \\
(0.031)\end{array}$ & $\begin{array}{c}0.191 \\
(0.121)\end{array}$ \\
\hline \multirow[t]{6}{*}{ Province } & Ontario & Ref. & Ref. \\
\hline & Quebec & $\begin{array}{c}0.002 \\
(0.019)\end{array}$ & $\begin{array}{l}-0.047 \\
(0.075)\end{array}$ \\
\hline & Manitoba & $\begin{array}{l}-0.005 \\
(0.021)\end{array}$ & $\begin{array}{l}-0.060 \\
(0.082)\end{array}$ \\
\hline & Saskatchewan & $\begin{array}{c}-0.123^{* * *} \\
(0.026)\end{array}$ & $\begin{array}{c}0.107 \\
(0.103)\end{array}$ \\
\hline & $\mathrm{R}^{2}$ & 0.085 & 0.016 \\
\hline & Num. obs. & 1,248 & 1,248 \\
\hline
\end{tabular}

Notes: (i) Least squares weighted by the inverse of the standard errors of the estimated individual preference parameters, ii) standard errors reported in parenthesis, iii) ${ }^{* * *} p<0.01$, ${ }^{* *} p<0.05,{ }^{*} p<0.1$. 


\subsection{The expected future gain of financial aid}

In this subsection, we focus on the relevant decision variables between cash payment and financial aid. Specifically, Table 4 compares the distribution of the expected discounted future utility gain against the period 0 utility of accepting a cash payment, for various types of financial aid packages and cash payments. Period 0 utility gains of accepting a cash payment (denoted by $\Delta($.$) ) are evaluated as the difference in the$ initial period utility of consumption evaluated at the reference consumption level $\left(c_{i}\right)$ plus a cash payment, and the initial period utility evaluated at the reference consumption level.

Table 4: Utilities of consumption and expected discounted future gain of financial aid

\begin{tabular}{lccccccc}
\hline & $\Delta\left(c_{100}\right)$ & $\Delta\left(c_{300}\right)$ & $\Delta\left(c_{700}\right)$ & $\beta \psi\left(\ell_{1000}\right)$ & $\beta \psi\left(\ell_{2000}\right)$ & $\beta \psi\left(g_{1000}\right)$ & $\beta \psi\left(g_{2000}\right)$ \\
\hline Min & 0 & 0 & 0 & 0 & 0 & 0 & 0 \\
1st Dec. & 32 & 83 & 157 & 2.8 & 2.8 & 47 & 96 \\
1st Quart. & 48 & 122 & 223 & 15 & 19 & 148 & 237 \\
40th Pct. & 58 & 144 & 260 & 29 & 36 & 186 & 282 \\
Median & 66 & 156 & 280 & 40 & 50 & 206 & 305 \\
Mean & 74 & 167 & 303 & 62 & 68 & 210 & 301 \\
SD & 144 & 152 & 282 & 144 & 142 & 167 & 190 \\
60th Pct. & 73 & 173 & 305 & 55 & 64 & 227 & 330 \\
3rd Quart. & 84 & 198 & 345 & 77 & 86 & 263 & 370 \\
9th Dec. & 103 & 229 & 407 & 117 & 122 & 321 & 438 \\
Max & 4281 & 4282 & 7599 & 3048 & 3014 & 3214 & 3448 \\
\hline Notes: (i) $\Delta\left(c_{x}\right)=u\left(c_{i}+x\right)-u\left(c_{i}\right),\left(\right.$ ii) $\beta \psi\left(\ell_{1000}\right)\left(\right.$ resp. $\left.\beta \psi\left(\ell_{2000}\right)\right)$ denotes the expected discounted \\
future utility gain associated with a $\$ 1,000$ (resp. $\$ 2,000)$ loan, (iii) $\beta \psi\left(g_{1000}\right)\left(\right.$ resp. $\left.\beta \psi\left(g_{2000}\right)\right)$ denotes \\
the expected discounted future utility gain associated with a $\$ 1,000($ resp. $\$ 2,000)$ grant.
\end{tabular}

First, as expected, for a given amount of financial aid, the median value of a grant exceeds the value of a loan. The median future utility gain of a $\$ 1,000$ grant is more than 5 times as high as the expected utility gain of a $\$ 1,000$ loan, while the median gain associated with a $\$ 2,000$ grant is 6 times as large as the expected gain of a $\$ 2,000$ loan. More generally, the distribution of the discounted expected future utility gains for a grant first-order stochastically dominates that of the expected future gains for a loan. Second, the utility gain associated with a grant increases with its size, with the distribution of the utility gains of a $\$ 2,000$ grant dominating that of a $\$ 1,000$ grant. A similar pattern holds for loans. This result shows that, in most parts of 
the distribution, the interest costs are not high enough to make a $\$ 2,000$ loan less attractive than a $\$ 1,000$ loan. Finally, the discounted expected future utility gains of the financial aid packages vary a lot across individuals, with the ratio of interdecile range over the median ranging from 1.1 (for a $\$ 2,000$ grant) to as much as 2.9 (for a $\$ 1,000$ loan).

We now examine the utility gains of accepting a cash payment. The distributions of the utility gains associated with a $\$ 300$ and $\$ 700$ cash payments dominate that of both types of loans. This is also true throughout most of the distribution of the utility gains associated with a smaller $\$ 100$ cash payment. On the other hand, the sign of the value of immediate cash versus grant varies across the distribution, with the median utility gain of accepting a $\$ 700$ cash payment ranging between the median gain of a $\$ 1,000$ grant and that of a $\$ 2,000$ grant.

Taken together, these results already provide suggestive evidence that the willingnessto-pay for financial aid packages is heterogeneous across high school students. However, our estimates allow us to go beyond the marginal distributions of utility gains associated with cash payments and financial aid, and directly compute individual-specific willingnesses-to-pay for the different types of financial aid packages that are proposed in the experiment. We report and discuss the estimated distributions of the willingness-to-pay for various types of financial aid packages in Section 7.3.

\subsection{Borrowing constraints and the value of financial aid}

\subsubsection{Measurement}

In this section, we combine the observed choices between cash transfers and financial aid packages with our model to evaluate the monetary values associated with the option to take up the various types of financial aid. Before doing so, it is important to examine the ability of our model to fit the financial aid decisions from the experiment. Table A6 in Appendix D reports the empirical frequencies of financial aid acceptance and the predicted probabilities, for each of the 17 financial aid choices to exercise. Our model generally fits the data reasonably well, with a couple of exceptions. Most notably, we underestimate the take-up rates of a $\$ 1,000$ grant and of the hybrid package (\$1,000 loan and $\$ 1,000$ grant) against a $\$ 700$ cash payment, while we overestimate 
the take-up rates for a $\$ 2,000$ loan against a $\$ 25$ cash payment. $^{26}$

In the following, we estimate individual-specific values of each type of grant, loan and hybrid loan that are proposed in the context of the experiment. Put into a public policy perspective, these estimates can be interpreted as uncovering the willingnessto-pay for a counterfactual expansion in higher education financial aid offers. In that sense, the experiment we use in the paper allows us to go beyond take-up rates by exploring the intensive margin of the demand for college financial aid.

We choose to pay specific attention to the willingness-to-pay for loans, which, unlike the willingness-to-pay for grants, are a natural measure of the tightness of individual borrowing constraints. While constrained students may attach a significant value to the opportunity of taking up a loan at the market rate, unconstrained students should only attach small or negligible values to those redundant opportunities. ${ }^{27}$

Specifically, let $c_{i q}^{m}$ be the incremental level of consumption that makes individuals indifferent between current consumption $\left(c_{i}+c_{i q}^{m}\right)$ and the financial aid package at question $q$. For such a value, we have

$$
u\left(c_{i}, \theta_{i}\right)+\beta_{i} \psi_{i q}=u\left(c_{i}+c_{i q}^{m}, \theta_{i}\right)
$$

After a few steps of algebra, we obtain:

$$
c_{i q}^{m}= \begin{cases}\exp \left(\frac{1}{1-\theta_{i}} \log \left(\left(1-\theta_{i}\right) \beta_{i} \psi_{i q}+c_{i}^{1-\theta_{i}}\right)\right)-c_{i} & \text { if } \theta_{i} \neq 1 \\ \exp \left(\beta_{i} \psi_{i q}+\log \left(c_{i}\right)\right)-c_{i} & \text { if } \theta_{i}=1\end{cases}
$$

$c_{i q}^{m}$ is the maximum consumption increase that one would be willing to trade in order to secure the financial aid package. Throughout the rest of the paper, we use

\footnotetext{
${ }^{26}$ In order to examine the importance of allowing for heterogeneous time and risk preference parameters, we also have estimated a constrained specification of our model with homogeneous discount factors and relative risk aversion parameters (results available from the authors upon request). While the estimated discount factor and risk aversion parameters (equal to 0.78 and 0.67 , respectively) are close to the mean of the corresponding empirical distributions from our preferred specification, the fit of this restricted model is much less satisfactory.

${ }^{27}$ In principle, the willingness-to-pay for loans may also capture the hassle cost associated with student loan application outside of the experiment. However, for the case of Federal student loans in Canada, the (online) application process requires filling one form only, and is overall fairly easy and quick. As a result, and in contrast with the Free Application for Federal Student Aid (FAFSA) process in the United States, the hassle cost seems unlikely to play a major role in this context.
} 
$c_{i q}^{m}$ as the individual-specific measure of the willingness-to-pay for the financial aid package offered in question $q$.

\subsubsection{Willingness-to-pay for financial aid}

In Table 5 below, we summarize the distributions of the estimated willingness-to-pay for the three types of financial aid packages (loans, grants and hybrid loans) of sizes $\$ 1,000$ and $\$ 2,000{ }^{28}$ Our results indicate that the median high school student would be willing to forego a $\$ 58.6$ increase in current consumption to secure a $\$ 1,000$ loan at the market interest rate in the near future. The willingness-to-pay for a $\$ 1,000$ loan is highly heterogeneous across students, with an interdecile range equal to $\$ 180$. While a quarter of the students are willing to sacrifice more than $\$ 116$ for the option to take up a $\$ 1,000$ loan, students in the bottom quartile are only willing to sacrifice less than $\$ 20$. In the next subsection we will examine how much of this heterogeneity is attributable to risk and time preference parameters, skills, as well as family background, socio-economic and geographical characteristics.

Table 5: The distribution of willingness-to-pay

\begin{tabular}{lcccccccc}
\hline Quantiles & \multicolumn{3}{c}{$\$ 1,000$} & & \multicolumn{3}{c}{$\$ 2,000$} \\
\cline { 2 - 4 } \cline { 6 - 8 } 1st Dec. & Loan & Grant & Hybrid & & Loan & Grant & Hybrid \\
\cline { 2 - 4 } \cline { 6 - 8 } 1st Quart. & 20.29 & 50.81 & 55.43 & & 5.95 & 128.4 & 118 \\
Median & 58.58 & 396.1 & 372.2 & & 82.26 & 678.4 & 504.7 \\
3rd Quart. & 116 & 556.1 & 509.1 & & 141.7 & 923.1 & 664.2 \\
9th Dec. & 183.9 & 721.8 & 649.8 & & 207.9 & 1199 & 828.1 \\
\hline \multicolumn{1}{c}{ Note: Amounts are in Canadian dollars. } & & & &
\end{tabular}

Put into a public policy perspective, a grant is equivalent to a tuition reduction, or a higher education subsidy. Not surprisingly, the value of a grant is typically much larger. The median student would be willing to trade in $\$ 396$ increase of their current

\footnotetext{
${ }^{28}$ For the ease of exposition, we focus hereafter on financial aid packages of sizes $\$ 1,000$ and $\$ 2,000$. Estimation results for alternative amounts of financial aid are available from the authors upon request.
} 
consumption for the option to take up a $\$ 1,000$ grant. Contrary to loans, only a small proportion of the population attaches low values to grant availability. For instance, less than $10 \%$ of the students would sacrifice less than $\$ 50$ for a $\$ 1,000$ grant, while around half of them would do so for a $\$ 1,000$ loan. More generally, for both amounts of financial aid $(\$ 1,000$ and $\$ 2,000)$, the distribution of the willingness-to-pay for a grant stochastically dominates that of a loan.

Turning to the hybrid packages, adding a loan to a grant generally has a small negative impact on the value of the package. This pattern holds true in most parts of the distributions of the willingness-to-pay. In practice, taking up a hybrid loan involves taking up both the grant and the loan components of the package. As a result, how much students are willing to trade for a hybrid package versus a single grant depends on the incremental value of a loan, as well as on the interest cost associated with it. Our results indicate that, in this context, the latter effect dominates. At any rate, this provides additional evidence that our model fits the descriptive patterns previously reported in Section 3 (Figure 2).

Finally, for loans, grants as well as hybrid loans, the value of the package generally increases with the size of the financial aid. Specifically, the distribution of the willingness-to-pay for a $\$ 2,000$ loan (grant) stochastically dominates that of a $\$ 1,000$ loan (grant), while a (\$2,000 loan, $\$ 2,000$ grant) hybrid loan also dominates that of a (\$1,000 loan, $\$ 1,000$ grant) hybrid loan. In particular, the results for loans provide suggestive evidence that, at least for a subset of the students in the sample, getting access to a $\$ 1,000$ loan is not enough to remove higher education credit constraints.

One can quantify the magnitude of, and heterogeneity in credit market imperfections by converting the willingness-to-pay for any given loan into the interest rate wedge that students would be willing to pay on top of the prevailing $\left(r_{0}=5.7 \%\right)$ market interest rate in order to secure the option to take up that loan. Specifically, for a given loan of size $l$ and willingness-to-pay $c_{m}$, we define the effective interest rate as the interest rate, denoted by $r_{1}\left(l, c_{m}\right)$, such that:

$$
\left(1+r_{1}\left(l, c_{m}\right)\right)\left(l-c_{m}\right)=\left(1+r_{0}\right) l
$$

where $l-c_{m}$ is the principal of the loan net of the willingness-to-pay, and $\left(1+r_{0}\right) l$ is the total repayment (principal plus interest fees). Note that $r_{1}\left(l, c_{m}\right)$ is larger than $r_{0}$ 
for any positive willingness-to-pay $c_{m}$. We report in Table 6 below the distribution of the interest rate wedges $\left(r_{1}\left(l, c_{m}\right)-r_{0}\right)$ associated with a $\$ 1,000$ loan and a $\$ 2,000$ loan: 
Table 6: The distribution of interest rate wedges (in percentage points)

\begin{tabular}{lcc}
\hline Quantiles & $\$ 1,000$ loan & $\$ 2,000$ loan \\
\hline 1st Dec. & 0.45 & 6.02 \\
1st Quart. & 2.19 & 7.50 \\
Median & 6.58 & 10.2 \\
3rd Quart. & 13.9 & 13.8 \\
9th Dec. & 23.8 & 18.0 \\
\hline
\end{tabular}

Note: Interest rate wedges are computed with respect to the prevailing market interest rate of $5.7 \%$.

These results indicate that most of the students in our sample are willing to pay a sizable interest rate premium above the prevailing market rate for the option to take up a loan. The median interest rate premium students would be willing to pay is large and equal to $6.58(10.2)$ percentage points for a $\$ 1,000(\$ 2,000)$ loan, respectively. ${ }^{29}$ As expected given the results on the willingness-to-pay for loans documented earlier, the interest rate premia also exhibit much heterogeneity across students. For the case of $\$ 1,000$ loans, the interest wedge ranges from 0.45 to 23.8 percentage points for the first and the last decile, respectively. Overall, these results point to the existence of credit constraints, in the form of frictions in the market for college loans, which affect a substantial share of high school students in Canada. Our estimates further show that a non-negligible fraction of high school students attach pretty large values to the option to take up a college loan. ${ }^{30}$ From a policy standpoint, our findings indicate that expanding higher education financial aid may in fact be socially desirable in this context, in spite of the Canadian higher education system being already heavily subsidized. ${ }^{31}$

\footnotetext{
${ }^{29}$ Interest rate wedges are lower for a $\$ 1,000$ loan than for a $\$ 2,000$ loan from the third quartile. This pattern is consistent with the willingness-to-pay increasing less with the amount of the loan in the top part of the distribution.

${ }^{30}$ To the extent that some individuals in the sample are likely to have low, or even zero subjective probabilities of enrolling in college, our results effectively provide a lower bound on the value attached to financial aid expansion among those students who anticipate enrolling in higher education. In practice $9.6 \%$ of the individuals in the sample have refused all financial offers that included a grant, presumably indicating a very small subjective probability of attending higher education for those students.

${ }^{31}$ In Appendix E, we report the distribution of the willingness-to-pay separately for Ontario and
} 


\subsubsection{Statistical decomposition}

We now examine the determinants of the value attached to financial aid. Before estimating marginal effects, we evaluate the relative importance of the main components of the willingness-to-pay for financial aid, namely (i) preference parameters (risk aversion and discount factors), (ii) skills (numeracy test score), (iii) family background characteristics (parental income and education) and (iv) other socio-economic and geographical variables such as gender, province, an indicator for living in a rural area, and family composition.

Understanding the determinants of the willingness-to-pay for financial aid is important from a policy standpoint. Notably, if skills or family background characteristics play an important role in this decomposition then these results may provide some guidance regarding the optimal targeting of higher education financial aid opportunities. On the other hand, if most of the variation in willingness-to-pay is attributable to risk and time preferences, then identifying who would benefit more from an expansion in higher education financial aid would prove much more challenging as these preferences are typically unknown to the policy maker.

Since our model is highly non-linear, there are multiple possible ways to decompose the willingness-to-pay. In the following we simply regress linearly the willingness-topay on various sets of characteristics. We then compute the adjusted coefficient of determination (Adjusted $R^{2}$ ) associated with each specification, and divide it by the Adjusted $R^{2}$ obtained when all four groups of determinants (i)-(iv) are included. The corresponding ratio can be interpreted as a measure of the relative importance of each group of variables.

As we did before, we focus our analysis on the willingness-to-pay for a $\$ 1,000$ loan and a $\$ 1,000$ grant. The decomposition results are reported in Table 7 . We highlight two main takeaways. First, as indicated by the ratios of adjusted $R^{2}(0.52$ for loans and 0.61 for grants), time and risk preference parameters are more important than all other determinants taken together. This is true for both loans and grants. A

Québec. Our estimates are consistent with the institutional differences across these two provinces. In particular, the distribution of the willingness-to-pay for a $\$ 1,000$ loan in Ontario dominates almost everywhere the distribution in Québec, consistent with higher levels of (net) tuition fees in Ontario than in Québec. 
second noteworthy finding is the low incremental explanatory power of numeracy test scores and parental background variables. For the case of a $\$ 1,000$ loan, the relative explanatory power increases by about $15 \%$ (from 0.52 to 0.60 ), while it increases by less than $7 \%$ only (from 0.61 to 0.65 ) for a $\$ 1,000$ grant. Overall, these results provide evidence that time and risk preference parameters play a dominant role in accounting for the variation across individuals in willingness-to-pay for financial aid. As such, our findings highlight the importance of collecting data on individual time and risk preferences to improve our understanding of educational financing decisions. Next, we report and discuss the marginal effects associated with those preference parameters, as well as with the numeracy scores and background characteristics.

Table 7: Statistical decomposition

\begin{tabular}{|c|c|c|c|c|c|c|c|c|}
\hline \multirow[b]{3}{*}{ Ratio Adjusted $R^{2}$} & \multicolumn{4}{|c|}{$c^{m}\left(\ell_{1000}\right)$} & \multicolumn{4}{|c|}{$c^{m}\left(g_{1000}\right)$} \\
\hline & (1) & $(2)$ & (3) & $(4)$ & (1) & $(2)$ & (3) & (4) \\
\hline & 0.52 & 0.52 & 0.60 & 1 & 0.61 & 0.61 & 0.65 & 1 \\
\hline Risk and Discounting & Yes & Yes & Yes & Yes & Yes & Yes & Yes & Yes \\
\hline Individual Skills & & Yes & Yes & Yes & & Yes & Yes & Yes \\
\hline $\begin{array}{l}\text { Parental education and in- } \\
\text { come }\end{array}$ & & & Yes & Yes & & & Yes & Yes \\
\hline $\begin{array}{l}\text { Geography and Family } \\
\text { structure }\end{array}$ & & & & Yes & & & & Yes \\
\hline
\end{tabular}

\subsubsection{Explaining the willingness-to-pay}

We now turn to the marginal effects of parental background variables and other observed attributes and preferences on the willingness-to-pay for financial aid. Table 8 below reports the average marginal effects for two types of financial aid packages, namely a $\$ 1,000$ loan and a $\$ 1,000$ grant. $^{32}$

\footnotetext{
${ }^{32}$ The fact that the magnitudes of the marginal effects tend to be larger for a $\$ 1,000$ grant than for a $\$ 1,000$ loan partly reflects the difference in scale across both outcomes, with the standard deviation of the willingness-to-pay for a $\$ 1,000$ grant being equal to $\$ 223$, against $\$ 77$ for a $\$ 1,000$ loan.
} 
Table 8: Explaining the willingness-to-pay (Average Marginal Effects)

\begin{tabular}{|c|c|c|}
\hline \multirow{3}{*}{$\theta$} & $c_{m}\left(\ell_{1000}\right)$ & $c_{m}\left(g_{1000}\right)$ \\
\hline & $3.70^{* * *}$ & $6.03^{* * *}$ \\
\hline & $(0.89)$ & $(0.13)$ \\
\hline \multirow[t]{2}{*}{$\beta$} & $33.57^{* * *}$ & $49.60^{* * *}$ \\
\hline & $(9.70)$ & $(10.30)$ \\
\hline \multirow[t]{2}{*}{ Numeracy } & $-0.07^{* *}$ & $0.75^{* * *}$ \\
\hline & $(0.04)$ & $(0.14)$ \\
\hline $0-20 K$ & Ref. & Ref. \\
\hline \multirow[t]{2}{*}{$20-40 \mathrm{~K}$} & $-1.10^{* * *}$ & $-0.38^{* *}$ \\
\hline & $(0.23)$ & $(0.19)$ \\
\hline \multirow[t]{2}{*}{$40-60 \mathrm{~K}$} & $2.40^{* * *}$ & $-0.69^{* * *}$ \\
\hline & $(0.30)$ & $(0.13)$ \\
\hline \multirow[t]{2}{*}{$60-80 \mathrm{~K}$} & $-0.42^{* *}$ & $2.50^{* * *}$ \\
\hline & $(0.23)$ & $(0.41)$ \\
\hline \multirow[t]{2}{*}{$80-100 \mathrm{~K}$} & $-0.78^{* * *}$ & 0.09 \\
\hline & $(0.13)$ & $(0.08)$ \\
\hline \multirow[t]{2}{*}{$+100 \mathrm{~K}$} & 0.13 & $-0.54^{* * *}$ \\
\hline & $(0.07)$ & $(0.13)$ \\
\hline Drop-out & Ref. & Ref. \\
\hline \multirow[t]{2}{*}{ High-school } & -0.64 & 1.70 \\
\hline & $(0.14)$ & $(0.28)$ \\
\hline \multirow[t]{2}{*}{ Vocational College } & 0.59 & 2.10 \\
\hline & $(0.59)$ & $(0.65)$ \\
\hline \multirow[t]{2}{*}{ College } & -0.26 & 0.70 \\
\hline & $(0.25)$ & $(0.32)$ \\
\hline Ontario & Ref. & Ref. \\
\hline \multirow[t]{2}{*}{ Quebec } & -0.58 & -0.20 \\
\hline & $(0.12)$ & $(0.05)$ \\
\hline \multirow[t]{2}{*}{ Manitoba } & 1.10 & 1.70 \\
\hline & $(0.20)$ & $(0.26)$ \\
\hline \multirow[t]{2}{*}{ Saskatchewan } & 2.10 & -0.97 \\
\hline & $(0.34)$ & $(0.17)$ \\
\hline
\end{tabular}

Notes: (i) The entries in this table are computed as the sample averages of the marginal effects evaluated at the observed values of the vector of covariates (Average Marginal Effects), (ii) marginal effects in standard deviation units for all continuous characteristics ( $\theta, \beta$, and Numeracy), (iii) standard errors reported in parenthesis, (iv) ${ }^{* * *} p<0.01,{ }^{* *} p<$ $0.05,{ }^{*} p<0.1$. 
We first examine the effects of parental income. There is a large empirical literature on the relationship between parental income and schooling attainment (Heckman and Mosso, 2014). Economists have long debated on the magnitude of the causal effects of parental income on educational outcomes, in particular college enrollment. Identifying those effects is a complicated task as family income is also likely correlated with individual abilities, as well as preferences for schooling. The experiment used in this paper allows us to go beyond evaluating the impact of parental income on schooling attainment as we can directly quantify how the willingness-to-pay for education financial aid, a measure that increases with the anticipated intensity of credit constraints, vary with family income. Doing so is also an important step towards evaluating the effectiveness of publicly provided financial aid policies that are meant to equalize opportunities across income groups. The results reported in Table 8 illustrate the differences in willingness-to-pay across income classes, using as a reference those who earn $\$ 20,000$ or less. The results indicate that the willingness-to-pay for a $\$ 1,000$ loan is non-linear and non-monotonic as the highest willingness-to-pay is found for the $\$ 40,000-\$ 60,000$ income group. However, the marginal effects across income groups are very small. For instance, on average, young individuals raised in families earning $\$ 40,000-\$ 60,000$ would only be willing to pay $\$ 2.4$ more for the option to take up a $\$ 1,000$ loan, relative to the lowest income reference group. This is consistent with the very low explanatory power associated with parental education and income that was documented in Table 7. A similar pattern holds for grants. The highest willingness-to-pay for a $\$ 1,000$ grant is found for students from the $\$ 60,000-\$ 80,000$ income group, who would pay only $\$ 2.5$ more than those from the reference group. Consistent with the low explanatory power of those characteristics, the marginal effects of parental education on the willingness-to-pay for a $\$ 1,000$ loan and a $\$ 1,000$ grant are also generally very small.

The co-existence of positive and sizable values attached to loans and grants, documented in Section 7.3.2 (Table 5), with the quasi-independence of the willingnessto-pay with respect to parental income indicates two important features of the Canadian higher education financing system. First, the median Canadian high school student is not satiated with financial aid opportunities, and the expected marginal utility of financial aid is non-negligible. Second, it does appear that the higher education 
public policies in place in Canada are successful in equalizing the marginal utility of financial aid opportunities across various income groups, as differences in family income have pretty much no impact on the value that young individuals would attach to a counterfactual expansion in higher education financial aid opportunities.

Finally, as was already noted in the previous section, there is clear evidence that individual differences in the willingness-to-pay for financial aid are mostly explained by deep (time and risk) preference parameters. We now discuss their marginal effects. The effect of the discount factor is easily predictable as the structure of the experiment implies that the benefit of financial aid can only be experienced in the future while the cash payment is practically immediate. Indeed, as shown in Table 8, the marginal effect of the discount factor on the willingness-to-pay for grants and loans are positive and significant, both statistically and economically. All else equal, increasing the discount factor by one standard deviation leads to a $\$ 34(\$ 50)$ increase in the willingness-to-pay for a $\$ 1,000$ loan ( $\$ 1,000$ grant). This marginal effect is in particular much larger than any of the effects associated with a $\$ 20,000$ income differential.

However, the marginal effect of risk aversion on the willingness-to-pay for grants or loans is more intricate because risk aversion affects not only the value of accepting a cash payment but also the value of financial aid, with the effect of risk aversion on the value of financial aid being ambiguous. ${ }^{33}$ Indeed, while high-school students who are more risk averse are also those who would benefit more from the future consumption smoothing opportunity provided by financial aid, individuals who accept financial aid can only exercise the option to take up a loan or a grant if they end up enrolling in higher education. Those who are more risk averse and who are also not certain of entering higher education, or are not sure when they are likely to do so, will be particularly sensitive to the latter feature. As a consequence, it is in theory not possible to sign unambiguously the effect of risk aversion on the willingness-to-pay for financial aid. Because both individual-specific enrollment uncertainty and future parental transfers are unobserved in our context, our model is not capable of separating those two channels, and, while interesting, any discussion about their relative importance

\footnotetext{
${ }^{33}$ Although with CRRA preferences the effect of risk aversion on the marginal utility of immediate consumption is in theory ambiguous too, and depends on the level of background consumption, it is always negative in our case since the background consumption happens to be larger than 1 for all the individuals in the sample.
} 
would lie beyond the scope of the paper. At this stage, we only note that the marginal effect of a one standard deviation increase in risk aversion on the willingness-to-pay for a $\$ 1,000$ grant and a $\$ 1,000$ loan are both positive (equal to around $\$ 4$ for loans and $\$ 6$ for grants), but are 8 to 10 times smaller than the marginal effects of discount factors.

\section{Conclusion}

In this paper, we estimate the distribution of the willingness-to-pay for higher education financial aid using data from a field experiment conducted in Canada where high school students had to choose between immediate cash payments and various types of higher education financing packages. Our model of financial aid acceptance decisions is based on an explicit trade-off between the increase in current utility following an immediate cash payment and the expected future gain associated with a specific financial aid package. As the experiment also allows us to estimate the distributions of individual risk aversion and discount factors, we are able to uncover how preference parameters for time and risk affect the willingness-to-pay for the various types of financial aids.

We find that the majority of students attach a sizable value to accessing student loans. Consistent with the existence of significant frictions in the market for college loans, we find that the median high school student in our sample would be willing to pay a large 6.6 percentage points interest rate premium on top of the prevailing market rate to secure a $\$ 1,000$ loan. The median interest rate premium is even higher for a $\$ 2,000$ loan, at about 10 percentage points. Taken together, these findings point to the existence of credit constraints affecting a sizable share of the population of high school students.

Our results also disclose a large degree of heterogeneity in both risk aversion and discount rates. The majority of the students exhibit a mild degree of risk aversion, while the distribution of discount factors is bimodal with individuals with low discount factors coexisting with forward-looking individuals. Interestingly, we find that the willingness-to-pay for financial aid is dominated by individual preferences. The value of financial aid is found to increase strongly with individual discount factors, while 
risk aversion also has a positive but much smaller effect on willingness-to-pay. After conditioning on individual preferences, family background characteristics only play a relatively modest role in the decision to accept a financial aid offer.

Our findings suggest a number of interesting avenues for future research. First, we believe that more effort should be devoted at investigating the role of time and risk preferences in educational financing decisions and schooling choices more broadly. Indeed, our results show that those preference parameters play a crucial role in financial aid acceptance decisions. Second, data availability has confined us to the analysis of financing decisions prior to actual college enrollment. It would be interesting to combine this educational financing experiment with observational data on subsequent outcomes to gain additional insights into the effects of improving higher education financing opportunities on educational as well as future labor market outcomes. 


\section{References}

Andersen, S., G. W. Harrison, M. I. Lau, and E. E. Rutstrom (2008). Eliciting risk and time preferences. Econometrica $76(3), 583-618$.

Andreoni, J. and C. Sprenger (2012). Estimating time preferences from convex budgets. American Economic Review 102(7), 3333-3356.

Arcidiacono, P., V. J. Hotz, and S. Kang (2012). Modeling college major choices using elicited measures of expectations and counterfactuals. Journal of Econometrics 166(1), $3-16$.

Arcidiacono, P., H. Sieg, and F. Sloan (2007). Living rationally under the volcano? an empirical analysis of heavy drinking and smoking. International Economic Review 48 , $37-65$.

Belley, P., M. Frenette, and L. Lochner (2014). Post-secondary attendance by parental income in the U.S. and Canada: do financial aid policies explain the differences? Canadian Journal of Economics 47(2), 664-696.

Belley, P. and L. Lochner (2007). The changing role of family income and ability in determining educational achievement. Journal of Human Capital 1(1), 37-89.

Belzil, C. and J. Hansen (2004). Earnings Dispersion, Risk Aversion and Education, Volume 33 of Research in Labor Economics, pp. 335-358. Greenwich, Conn.: JAI.

Brodaty, T., R. J. Gary-Bobo, and A. Prieto (2014). Do risk aversion and wages explain educational choices? Journal of Public Economics 117, 125-148.

Brown, M., J. K. Scholz, and A. Seshadri (2012). A new test of borrowing constraints for education. Review of Economic Studies 79(2), 511-538.

Cameron, S. V. and J. J. Heckman (1998). Life cycle schooling and dynamic selection bias: Models and evidence for five cohorts of american males. Journal of Political Economy 106(2), 262-333.

Cameron, S. V. and C. Taber (2004). Estimation of educational borrowing constraints using returns to schooling. Journal of Political Economy 112(1), 132-182. 
Card, D. (1995). Earnings, schooling, and ability revisited, Volume 14 of Research in Labor Economics, pp. 23-28. Greenwich, Conn.: JAI.

Carneiro, P. and J. J. Heckman (2002). The evidence on credit constraints in post-secondary schooling. Economic Journal 112(482), 705-734.

Coller, M. and M. Williams (1999). Eliciting individual discount rates. Experimental Economics 2(2), 107-127.

Delavande, A. and B. Zafar (2014). University choice: The role of expected earnings, non-pecuniary outcomes and financial constraints. Working paper.

Frederick, S., G. Loewenstein, and T. O'Donoghue (2002). Time discounting and time preference: a critical review. Journal of Economic Literature 40(2), 351-401.

Geweke, J. and M. Keane (2000). Bayesian inference for dynamic discrete choice models without the need for dynamic programming. In R. Mariano, T. Schuermann, and M. Weeks (Eds.), Simulation-based inference in econometrics: methods and applications, pp. 100-131. Cambridge: Cambridge University Press.

Hansen, J. and X. Liu (2013). A structural model of educational attainment in canada. IZA Discussion Paper 7237.

Harrison, G. W. and J. A. List (2004). Field experiments. Journal of Economic Literature 42(4), 1009-1055.

Heckman, J. J. and S. Mosso (2014). The economics of human development and social mobility. Annual Review of Economics 6, 689-733.

Holt, C. A. and S. K. Laury (2002). Risk aversion and incentive effects. American Economic Review 92(5), 1644-1655.

Johnson, M. T. (2013). Borrowing constraints, college enrollment, and delayed entry. Journal of Labor Economics 31(4), 669-725.

Keane, M. P. and K. I. Wolpin (1997). The career decisions of young men. Journal of Political Economy 105(3), 473-522.

Keane, M. P. and K. I. Wolpin (2001). The effect of parental transfers and borrowing constraints on educational attainment. International Economic Review 42(4), 1051-1103. 
Lang, K. (1993). Ability bias, discount rate bias, and the return to education. Manuscript, Boston University, Department of Economics.

Lochner, L. J. and A. Monge-Naranjo (2011). The nature of credit constraints and human capital. American Economic Review 101(6), 2487-2529.

Lochner, L. J. and A. Monge-Naranjo (2012). Credit constraints in education. Annual Review of Economics 4, 225-256.

Lochner, L. J. and A. Monge-Naranjo (2016). Student loans and repayment: theory, evidence, and policy. Volume 5 of Handbook of the Economics of Education, Chapter 8, pp. 397-478. Amsterdam: North Holland.

Magnac, T. and E. Maurin (2008). Partial identification in monotone binary models: Discrete regressors and interval data. Review of Economic Studies 75(3), 835-864.

Magnac, T. and D. Thesmar (2002). Identifying dynamic discrete decision processes. Econometrica 70(2), 801-816.

Montmarquette, C. and C. Johnson (2015). The lack of loan aversion among canadian high school students. Canadian Journal of Economics 48(2), 585-611.

Murray, S., Y. Clermont, and M. Binkley (2005). The international adult literacy and skills survey. Technical report, Statistics Canada.

Neyman, J. and E. L. Scott (1948). Consistent estimates based on partially consistent observations. Econometrica 16(1), 1-32.

Sauer, R. M. (2004). Educational financing and lifetime earnings. Review of Economic Studies 71 (4), 1189-1216.

Stinebrickner, R. and T. R. Stinebrickner (2008). The effect of credit constraints on the college drop-out decision: A direct approach using a new panel study. American Economic Review 98(5), 2163-84.

Stinebrickner, R. and T. R. Stinebrickner (2014). A major in science? initial beliefs and final outcomes for college major and dropout. Review of Economic Studies 81(1), 426-472.

Wiswall, M. and B. Zafar (2015a). Determinants of college major choice: identification using an information experiment. Review of Economic Studies 82(2), 791-824. 
Wiswall, M. and B. Zafar (2015b). How do college students respond to public information about earnings? Journal of Human Capital 9(2), 117-169.

Zafar, B. (2013). College major choice and the gender gap. Journal of Human Resources 48, $545-595$. 


\section{Appendix (For Online Publication)}

\section{A The Millenium Foundation Field Experiment on Education Financing}

In this section, we provide additional details on the structure of the field experiment. An extensive discussion of the experiment and the sample is available in Montmarquette and Johnson (2015).

All subjects were presented with the full set of decisions and are paid for one randomly selected decision at the end of the session. The subjects were informed that they would be paid for one decision, but they did not know which one at the beginning of the session. The questions can be split into three groups. First, students must answer a set of questions aimed at measuring their rate of time preference. Table A1 illustrates the experiment where individuals are offered a choice between two payments of different values to be made at different points in time. This approach, originally developed by Coller and Williams (1999), allows to evaluate each subject's willingness to forgo present consumption for future consumption, and provides a measure of the discount rate.

A second set of questions relate to the measurement of risk attitudes. Students are presented with a sequence of binary choices between two lotteries in which risk is objectively stated. Table A2 presents the two strategies used for eliciting risk aversion. Both strategies consist of choosing between a lottery with average payoff and another one with extreme payoff, and identify the cutoff point where an agent switches from the average to the extreme lottery. The major difference between the two strategies lies in the fact that while the first one pins down a cut-off probability, the second identifies a cut-off payoff. These approaches pioneered by Holt and Laury (2002) are standard in the experimental literature to measure the degree of risk aversion.

The third group of questions, which constitutes the most original aspect of the field experiment, is a sequence of choices between a cash payment to be paid within one week from the day the experiment was carried, and the option to use a specific financial aid package covering educational expenses. The financial aid package is to be paid conditional on enrolling in a full-time program at any higher education 
Table A1: Discount rates questions

\begin{tabular}{|c|c|c|c|c|}
\hline \multicolumn{2}{|c|}{ Choices 1} & \multicolumn{2}{|c|}{ Choices 2} & \multirow{3}{*}{$\begin{array}{l}\text { Annual } \\
\text { Interest }(\%)\end{array}$} \\
\hline Payment & Payment & Payment & Payment & \\
\hline 1 day & 1 month & 1 day & 1 year & \\
\hline$\$ 75$ & $\$ 75.31$ & $\$ 75$ & $\$ 78.75$ & 5 \\
\hline$\$ 75$ & $\$ 75.63$ & $\$ 75$ & $\$ 82.5$ & 10 \\
\hline$\$ 75$ & $\$ 76.25$ & $\$ 75$ & $\$ 90.00$ & 20 \\
\hline$\$ 75$ & $\$ 78.13$ & $\$ 75$ & $\$ 112.5$ & 50 \\
\hline$\$ 75$ & $\$ 81.25$ & $\$ 75$ & $\$ 150.0$ & 100 \\
\hline$\$ 75$ & $\$ 87.5$ & $\$ 75$ & $\$ 225.0$ & 200 \\
\hline \multicolumn{2}{|c|}{ Choices 3} & \multicolumn{2}{|c|}{ Choices 4} & \\
\hline Payment & Payment & Payment & Payment & Annual \\
\hline 1 week & 1 month +1 week & 1 week & 1 year +1 week & Interest $(\%)$ \\
\hline$\$ 75$ & $\$ 75.31$ & $\$ 75$ & $\$ 78.75$ & 5 \\
\hline$\$ 75$ & $\$ 75.63$ & $\$ 75$ & $\$ 82.5$ & 10 \\
\hline$\$ 75$ & $\$ 76.25$ & $\$ 75$ & $\$ 90.00$ & 20 \\
\hline$\$ 75$ & $\$ 78.13$ & $\$ 75$ & $\$ 112.5$ & 50 \\
\hline$\$ 75$ & $\$ 81.25$ & $\$ 75$ & $\$ 150.0$ & 100 \\
\hline$\$ 75$ & $\$ 87.5$ & $\$ 75$ & $\$ 225.0$ & 200 \\
\hline
\end{tabular}


Table A2: Risk aversion lotteries

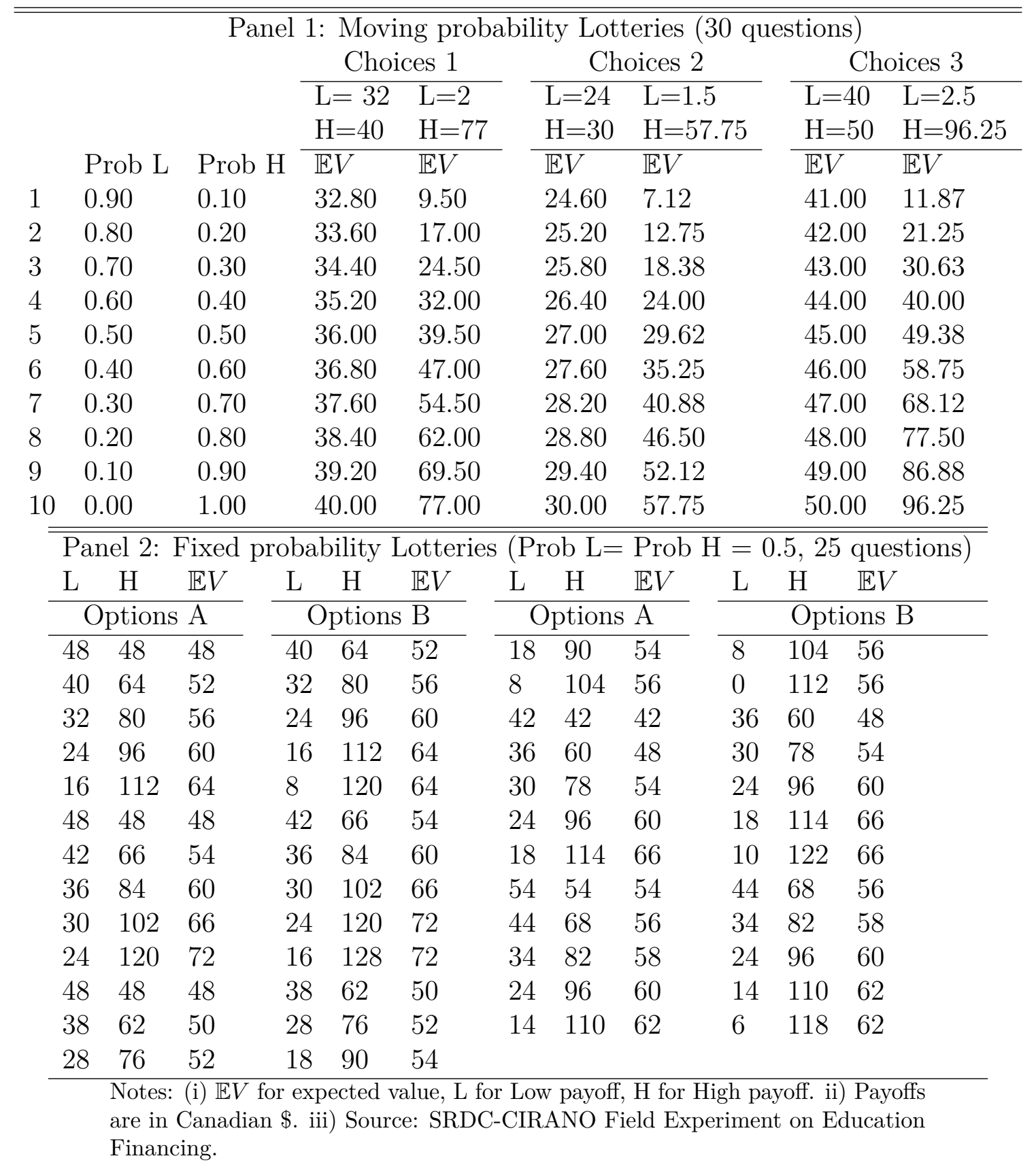


institution in the country (within 2 years). Grants and loans were defined as follows:

- Grants: Educational grants will be disbursed if a participant enrolls in a higher education institution for learning or training full time within two years from the date of experiment participation. The grant will cover direct and indirect costs related to the learning activity. For tuition fees, payments will be made directly to the education institution. Receipts will be required for the reimbursement of other costs.

- Loans: Educational loans will be disbursed if a participant enrolls in a higher education institution for learning or training full time. These loans will be available up to two years from the date of the experiment. The loans are repayable upon the completion of, or if the participants drops out of the program of study. The interest rate, which is the same as the one offered by the Canadian Federal Student Assistance program, is floating and is set at the prime rate plus $2.5 \% .^{34}$

In total, we consider three different types of subsidies: grants, loans, and hybrid loans which incorporate both a loan and a grant component. We use a total of 17 financial decisions, with 5 choices with a single loan offer, 7 choices with a single grant offer, and 5 hybrid offers. These decisions are summarized in Table A3.

In monetary terms, cash alternatives varied from $\$ 25$ to $\$ 700$, while grants and loans varied from $\$ 400$ to $\$ 4,000$. The variations in cash, and in the nature and the size of financial aid packages have a number of advantages. For instance, for a given cash payment offered and manipulating the financial parameters, we can uncover the relative values of a grant and a loan. Suppose instead that the financial aid package is fixed, we can also reveal the willingness to pay for a specific package by manipulating the cash payment. At the outset, it should be clear that these amounts are quite sizeable. Over the period considered, a grant of $\$ 2,000$ in 2008 would have covered $65 \%$ of yearly fee at University of Western Ontario and Queen's University, and almost $100 \%$ at McGill University and Université de Montréal. In addition, although tuition fees at vocational college are more dispersed, they are also

\footnotetext{
${ }^{34}$ The prime rate was equal to $3.2 \%$ on average over the period of interest.
} 
Table A3: Financial aid questions

\begin{tabular}{|c|c|c|c|c|c|}
\hline Type of package & Choices & Cash & Grant & Loan & Aid Take-up \\
\hline \multirow{5}{*}{ Single Loans } & 1 & 25 & 0 & 2,000 & 0.458 \\
\hline & 2 & 300 & 0 & 2,000 & 0.171 \\
\hline & 3 & 700 & 0 & 2,000 & 0.051 \\
\hline & 4 & 300 & 0 & 1,000 & 0.109 \\
\hline & 5 & 300 & 0 & 4,000 & 0.283 \\
\hline \multirow{5}{*}{ Standard Hybrid } & 6 & 25 & 1,000 & 1,000 & 0.834 \\
\hline & 7 & 300 & 1,000 & 1,000 & 0.637 \\
\hline & 8 & 700 & 1,000 & 1,000 & 0.389 \\
\hline & 9 & 300 & 400 & 400 & 0.287 \\
\hline & 10 & 300 & 2,000 & 2,000 & 0.727 \\
\hline \multirow{7}{*}{ Single Grants } & 11 & 25 & 1,000 & 0 & 0.886 \\
\hline & 12 & 100 & 1,000 & 0 & 0.826 \\
\hline & 13 & 300 & 1,000 & 0 & 0.686 \\
\hline & 14 & 700 & 1,000 & 0 & 0.412 \\
\hline & 15 & 300 & 500 & 0 & 0.384 \\
\hline & 16 & 300 & 2,000 & 0 & 0.764 \\
\hline & 17 & 300 & 4,000 & 0 & 0.835 \\
\hline
\end{tabular}

Notes: i) Amounts are in Canadian dollars, ii) Source: SRDC-CIRANO Field Experiment on Education Financing. 
subject to the same regulation and are comparable to those of universities. ${ }^{35}$ Put in 2015 Canadian dollars, the total cost of the experiment is around $\$ 1,000,000$.

The sample was recruited to generate meaningful comparisons by population group, gender, and low-, medium- or high-income status. The original project design called for a minimum sample size of 1,000 urban respondents with the goal of 200 participants per group of interest, with a total sample of 1,248 individuals. Table A4 summarizes the share of participants in several groups of interest. ${ }^{36}$

Over the day of the experiment, a numeracy test provided by the Center for Education Statistics was administered to all students. The test was based on the numerical component of the International Adult Literacy and Skills Survey project undertaken by numerous OECD countries between 1995 and 2005. The questions are meant to capture the capacity to perform numerical calculations. ${ }^{37}$ Students received a score between 0 and 500, which is used as a cognitive ability measure. ${ }^{38}$

\footnotetext{
${ }^{35}$ See Council of ministers of education of Canada (http://www.educationau-incanada.ca).

${ }^{36}$ Parental education is defined as the highest level of education of the parent who responded to the survey. Parental income is defined as the total income declared by the respondent, before tax deductions and measured in 2007, of all family members living in the household.

${ }^{37}$ More details can be found in Murray, Clermont, and Binkley (2005).

${ }^{38}$ In our empirical application, individual numeracy test score has been scaled to have variance one, and the mean is 5.1 .
} 
Table A4: Descriptive statistics of the sample

\begin{tabular}{llr}
\hline \hline Parental & Drop-out & $8 \%$ \\
Education & High-school & $25 \%$ \\
& Vocational College & $7 \%$ \\
& College & $61 \%$ \\
Parental & $0-20 \mathrm{~K}$ & $5 \%$ \\
Income & $20-40 \mathrm{~K}$ & $13 \%$ \\
& $40-60 \mathrm{~K}$ & $23 \%$ \\
& $60-80 \mathrm{~K}$ & $19 \%$ \\
& $80-100 \mathrm{~K}$ & $15 \%$ \\
& $+100 \mathrm{~K}$ & $24 \%$ \\
Location & Urban & $80 \%$ \\
& Rural & $20 \%$ \\
Province & Quebec & $30 \%$ \\
& Ontario & $29 \%$ \\
& Manitoba & $28 \%$ \\
& Saskatchewan & $13 \%$ \\
Citizen & Native & $94 \%$ \\
& Immigrant & $6 \%$ \\
\hline \multirow{7}{*}{ Gender } & Male & $46 \%$ \\
& Female & $54 \%$ \\
\hline
\end{tabular}

Source: SRDC-CIRANO Field Experiment on Education Financing. 


\section{B Parametrization}

$$
\begin{aligned}
c_{i}^{a} & =c_{0}+c_{1} \mathbb{1}_{\text {High-school }}^{p}+c_{2} \mathbb{1}_{\text {Voc college }}^{p}+c_{3} \mathbb{1}_{\text {College }}^{p} \\
& +c_{4} \mathbb{1}_{20-40 \mathrm{~K}}^{p}+c_{5} \mathbb{1}_{40-60 \mathrm{~K}}^{p}+c_{6} \mathbb{1}_{60-80 \mathrm{~K}}^{p}+c_{7} \mathbb{1}_{80-100 \mathrm{~K}}^{p}+c_{8} \mathbb{1}_{+100 \mathrm{~K}}^{p} \\
& +c_{9} \mathbb{1}_{\text {Quebec }}+c_{10} \mathbb{1}_{\text {Ontario }}+c_{11} \mathbb{1}_{\text {Saskatchewan }}+c_{12} \mathbb{1}_{\text {Rural }}^{p} \\
& +c_{13} \mathbb{1}_{\text {Female }}^{a}+c_{14} \mathbb{1}_{\text {Citizenship }}^{a}+c_{15} \mathbb{1}_{\text {Siblings -18 years }}^{a}+c_{16} \mathbb{1}_{\text {Siblings }+18 \text { years }}^{a}
\end{aligned}
$$

$$
\begin{aligned}
\psi_{i q}\left(g_{q}, \ell_{q}\right) & =\psi_{0}+\psi_{1} g+\psi_{2} g^{2}+\psi_{3} \ell+\psi_{4} \ell^{2}+\psi_{5} \ell \times g \\
& +\psi_{6} \beta+\psi_{7} \theta+\psi_{8} \beta \times g+\psi_{9} \theta \times g+\psi_{10} \beta \times \ell+\psi_{11} \theta \times \ell \\
& +\psi_{12} \mathrm{NU}+\psi_{13} \mathrm{NU}^{2}+\psi_{14} \mathrm{NU} \times \beta+\psi_{15} \mathrm{NU} \times \theta+\psi_{16} \mathrm{NU} \times g+\psi_{17} \mathrm{NU} \times \ell \\
& +\psi_{18} \mathbb{1}_{20-40 \mathrm{~K}}^{p}+\psi_{19} \mathbb{1}_{40-60 \mathrm{~K}}^{p}+\psi_{20} \mathbb{1}_{60-80 \mathrm{~K}}^{p}+\psi_{21} \mathbb{1}_{80-100 \mathrm{~K}}^{p}+\psi_{22} \mathbb{1}_{+100 \mathrm{~K}}^{p} \\
& +\psi_{23} \mathbb{1}_{\text {High-school }}^{p}+\psi_{24} \mathbb{1}_{\text {Voc college }}^{p}+\psi_{25} \mathbb{1}_{\text {College }}^{p}+\psi_{26} \mathbb{1}_{\mathrm{Quebec}}+\psi_{27} \mathbb{1}_{\text {Ontario }}+\psi_{28} \mathbb{1}_{\text {Saskatchewan }} \\
& +\psi_{29} \mathbb{1}_{\mathrm{QC}} \frac{g}{2180}+\psi_{30} \mathbb{1}_{\mathrm{ON}} \frac{g}{5667}+\psi_{31} \mathbb{1}_{\mathrm{SK}} \frac{g}{5064}+\psi_{32} \mathbb{1}_{\mathrm{QC}} \frac{\ell}{2180}+\psi_{33} \mathbb{1}_{\mathrm{ON}} \frac{\ell}{5667}+\psi_{34} \mathbb{1}_{\mathrm{SK}} \frac{\ell}{5064} \\
& +\psi_{35} \mathbb{1}_{20-40 \mathrm{~K}}^{p} \times g+\psi_{36} \mathbb{1}_{40-60 \mathrm{~K}}^{p} \times g+\psi_{37} \mathbb{1}_{60-80 \mathrm{~K}}^{p} \times g+\psi_{38} \mathbb{1}_{80-100 \mathrm{~K}}^{p} \times g+\psi_{39} \mathbb{1}_{+100 \mathrm{~K}}^{p} \times g \\
& +\psi_{40} \mathbb{1}_{20-40 \mathrm{~K}}^{p} \times \ell+\psi_{41} \mathbb{1}_{40-60 \mathrm{~K}}^{p} \times \ell+\psi_{42} \mathbb{1}_{60-80 \mathrm{~K}}^{p} \times \ell+\psi_{43} \mathbb{1}_{80-100 \mathrm{~K}}^{p} \times \ell+\psi_{44} \mathbb{1}_{+100 \mathrm{~K}}^{p} \times \ell \\
& +\psi_{45} \mathbb{1}_{20-40 \mathrm{~K}}^{p} \times \theta+\psi_{46} \mathbb{1}_{40-60 \mathrm{~K}}^{p} \times \theta+\psi_{47} \mathbb{1}_{60-80 \mathrm{~K}}^{p} \times \theta+\psi_{48} \mathbb{1}_{80-100 \mathrm{~K}}^{p} \times \theta+\psi_{49} \mathbb{1}_{+100 \mathrm{~K}}^{p} \times \theta \\
& +\psi_{50} \mathbb{1}_{20-40 \mathrm{~K}}^{p} \times \beta+\psi_{51} \mathbb{1}_{40-60 \mathrm{~K}}^{p} \times \beta+\psi_{52} \mathbb{1}_{60-80 \mathrm{~K}}^{p} \times \beta+\psi_{53} \mathbb{1}_{80-100 \mathrm{~K}}^{p} \times \beta+\psi_{54} \mathbb{1}_{+100 \mathrm{~K}}^{p} \times \beta \\
& +\psi_{55} \mathbb{1}_{\mathrm{HS}}^{p} \times g+\psi_{56} \mathbb{1}_{\mathrm{VC}}^{p} \times g+\psi_{57} \mathbb{1}_{\mathrm{CO}}^{p} \times g+\psi_{58} \mathbb{1}_{\mathrm{HS}}^{p} \times \ell+\psi_{59} \mathbb{1}_{\mathrm{VC}}^{p} \times \ell+\psi_{60} \mathbb{1}_{\mathrm{CO}}^{p} \times \ell \\
& +\psi_{61} \mathbb{1}_{\mathrm{HS}}^{p} \times \beta+\psi_{62} \mathbb{1}_{\mathrm{VC}}^{p} \times \beta+\psi_{63} \mathbb{1}_{\mathrm{CO}}^{p} \times \beta+\psi_{64} \mathbb{1}_{\mathrm{HS}}^{p} \times \theta+\psi_{65} \mathbb{1}_{\mathrm{VC}}^{p} \times \theta+\psi_{66} \mathbb{1}_{\mathrm{CO}}^{p} \times \theta \quad(12)
\end{aligned}
$$




\section{Background consumption}

Table A5: Background consumption (financial aid questions)

\begin{tabular}{rrr}
\hline & Estimates & St. errors \\
\hline Const & 1.84 & 0.01 \\
High-school & -0.09 & 0.02 \\
Vocational College & 0.63 & 0.01 \\
College & -0.05 & 0.01 \\
$20-40 \mathrm{~K}$ & -0.91 & 0.03 \\
$40-60 \mathrm{~K}$ & 0.39 & 0.04 \\
$60-80 \mathrm{~K}$ & 0.51 & 0.04 \\
$80-100 \mathrm{~K}$ & -0.46 & 0.04 \\
$+100 \mathrm{~K}$ & -0.27 & 0.05 \\
Urban & 0.03 & 0.01 \\
Male & 0.90 & 0.02 \\
Native & -1.75 & 0.00 \\
Quebec & -0.33 & 0.04 \\
Ontario & 0.45 & 0.03 \\
Saskatchewan & 0.39 & 0.01 \\
Siblings less than -18 & -0.11 & 0.01 \\
Siblings more than 18 & 0.02 & 0.01 \\
\hline
\end{tabular}




\section{Model fit}

Table A6: Model Fit

\begin{tabular}{|c|c|c|}
\hline Choices & $\begin{array}{c}\text { Predicted } \\
\text { Probabilities }\end{array}$ & $\begin{array}{c}\text { Empirical } \\
\text { Frequencies }\end{array}$ \\
\hline$c_{25} \mathrm{VS} g_{1000}$ & 0.90 & 0.89 \\
\hline$c_{100} \mathrm{VS} g_{1000}$ & 0.84 & 0.83 \\
\hline$c_{300} \mathrm{VS} g_{1000}$ & 0.64 & 0.69 \\
\hline$c_{700} \mathrm{VS} g_{1000}$ & 0.28 & 0.41 \\
\hline$c_{300} \mathrm{VS} g_{500}$ & 0.41 & 0.38 \\
\hline$c_{300} \mathrm{VS} g_{2000}$ & 0.82 & 0.76 \\
\hline$c_{300} \mathrm{VS} g_{4000}$ & 0.78 & 0.84 \\
\hline$c_{25} \mathrm{VS} \ell_{2000}$ & 0.63 & 0.46 \\
\hline$c_{300} \mathrm{VS} \ell_{2000}$ & 0.19 & 0.17 \\
\hline$c_{700} \mathrm{VS} \ell_{2000}$ & 0.04 & 0.05 \\
\hline$c_{300} \mathrm{VS} \ell_{1000}$ & 0.18 & 0.11 \\
\hline$c_{300} \mathrm{VS} \ell_{4000}$ & 0.28 & 0.28 \\
\hline$c_{25} \mathrm{VS} \ell_{1000}+g_{1000}$ & 0.89 & 0.83 \\
\hline$c_{300} \mathrm{VS} \ell_{1000}+g_{1000}$ & 0.60 & 0.64 \\
\hline$c_{700} \mathrm{VS} \ell_{1000}+g_{1000}$ & 0.24 & 0.39 \\
\hline$c_{300} \mathrm{VS} \ell_{400}+g_{400}$ & 0.35 & 0.29 \\
\hline$c_{300} \mathrm{VS} \ell_{2000}+g_{2000}$ & 0.74 & 0.73 \\
\hline
\end{tabular}

Note: $c, g$ and $\ell$ stand for cash, grant and loan, respectively. For example $c_{25}$ VS $g_{1000}$ refers to the choice between $\$ 25$ cash and $\$ 1,000$ grant, while $c_{25}$ VS $\ell_{1000}+g_{1000}$ refers to the choice between $\$ 25$ cash and the hybrid package ( $\$ 1,000$ loan and $\$ 1,000$ grant). 


\section{E Spatial heterogeneity}

In Table A7 below, we report the distribution of the willingness-to-pay for a $\$ 1,000$ loan, a $\$ 1,000$ grant and a hybrid financial aid package containing a $\$ 1,000$ loan and a $\$ 1,000$ grant, separately for Ontario and Québec. These two provinces, which are the most populated in Canada, are characterized by markedly different levels of tuition fees. Specifically, Québec has low average annual tuition $(\$ 2,180$ over the period of interest), while Ontario has significantly higher tuition rates $(\$ 5,667$ on average over the period of interest). Québec and Ontario do not only differ in terms of higher education tuition fees, but also in terms of financial aid generosity. The average amount of financial aid offers per student, as well as the fraction of the total financial aid that takes the form of grants is significantly higher in Québec than in Ontario. ${ }^{39}$ For a Québec resident, the median value of securing a $\$ 1,000$ loan is estimated to be $\$ 54$. On the other hand, the median young Ontarians, who are faced with higher tuition rates, would pay a higher amount $(\$ 71)$. More generally, the distribution of the willingness-to-pay in Ontario dominates almost everywhere the distribution in Québec. In particular, the first quartile, the median and the third quartile of the distribution of the willingness-to-pay are all significantly higher in Ontario than in Québec at the $5 \%$ level. At the third quartile, the values indicating the willingness-to-pay are equal to $\$ 137$ for Ontario and $\$ 100$ for Québec.

Students from Ontario also attach higher values to grants as well as hybrid loans than students from Québec. The median Ontarian high school student in our sample is willing to forego $\$ 458$ to secure a $\$ 1,000$ grant (45.8 cents per dollar), while the median student from Québec is willing to trade $\$ 360$ against a $\$ 1,000$ grant (36 cents per dollar). Differences for hybrid loans are of similar magnitude, with the median willingness-to-pay for a hybrid (\$1,000 loan, $\$ 1,000$ grant) package in Ontario being equal to $\$ 432$, against $\$ 334$ in Québec. These findings are consistent with the existence of significantly higher levels of (net) tuition fees in Ontario than in Québec.

\footnotetext{
${ }^{39}$ For more details regarding financial aid parameters in Canada, see Belley et al. (2014).
} 
Table A7: The distribution of the willingness-to-pay by province

\begin{tabular}{lcccccc}
\hline & \multicolumn{2}{c}{$c_{i}^{m}\left(\ell_{1000}\right)$} & \multicolumn{2}{c}{$c_{i}^{m}\left(g_{1000}\right)$} & \multicolumn{2}{c}{$c_{i}^{m}\left(\ell_{1000}+g_{1000}\right)$} \\
\hline & ON & QC & ON & QC & ON & QC \\
\hline 1st Dec. & 8.2 & 3.4 & 174 & 104 & 180 & 110 \\
1st Quart. & 28 & 22 & 310 & 226 & 300 & 214 \\
Median & 71 & 54 & 458 & 360 & 432 & 334 \\
3rd Quart. & 137 & 100 & 618 & 487 & 569 & 448 \\
9th Dec. & 191 & 159 & 776 & 580 & 707 & 530
\end{tabular}

Notes: (i) QC: Quebec, ON: Ontario. ii) Amounts are in Canadian dollars. 